\title{
Discrete Model Predictive Control-Based Maximum Power Point Tracking for PV Systems: Overview and Evaluation
}

\author{
Abderezak Lashab, Student Member, IEEE, Dezso Sera, Senior Member, IEEE, Josep M. Guerrero, \\ Fellow, IEEE, Laszlo Mathe, Senior Member, IEEE, and Aissa Bouzid
}

\begin{abstract}
The main objective of this work is to provide an overview and evaluation of discrete model predictive controlbased maximum power point tracking (MPPT) for PV systems. A large number of MPC based MPPT methods have been recently introduced in the literature with very promising performance, however, an in-depth investigation and comparison of these methods have not been carried out yet. Therefore, this paper has set out to provide an in-depth analysis and evaluation of MPC based MPPT methods applied to various common power converter topologies. The performance of MPC based MPPT is directly linked with the converter topology, and it is also affected by the accurate determination of the converter parameters, sensitivity to converter parameter variations is also investigated. The static and dynamic performance of the trackers are assessed according to the EN 50530 standard, using detailed simulation models and validated by experimental tests.

The analysis in this work aims to present a useful insight for practicing engineers and academic researchers when selecting the MPP tracker for their application.
\end{abstract}

Index Terms - Boost, Flyback, EN 50530, Grid connected, MPC, MPPT, Photovoltaic, Z-source inverter.

\section{INTRODUCTION}

$\mathrm{P}$ HOTOVOLTAIC (PV) systems are one among the fastest growing renewable energy generation technologies. Around half a million PV panels were installed every day all over the world in 2015 [1]. By 2050, the cumulative installed capacity of PV systems could reach $3000 \mathrm{GW}$, providing 4500 TWh per year, i.e. around $11 \%$ of global electricity production [2]. Concerning the price, from 2009 to 2016, the cost of PV modules has been reduced by five times and the cost of full PV systems has been reduced by almost three times [2].

The output power characteristic of the PV module is nonlinear and it depends on the meteorological conditions, such as solar irradiance and temperature. Usually, there is one operating point where the PV panel generates its maximum power. Also, the PV system efficiency can be degraded if the $\mathrm{PV}$ panel is not forced to operate at its maximum power at all times regardless of the environmental conditions [3]. Hence, a means that makes the PV module operate at its maximum

Abderezak Lashab and Aissa Bouzid are with Laboratoire d'Electrotechnique de Constantine, Université des Frère Mentouri, 25000 Constantine, Algeria. (e-mail: Abderezak.lashab@lec-umc.org; you.bouzid@yahoo.fr).

Dezso Sera, Josep M. Guerrero, and Laszlo Mathe are with the Departement of Energy Technology, Aalborg University, 9220 Aalborg, Denmark. (e-mail: des@et.aau.dk; joz@et.aau.dk; lam@et.aau.dk). power is required. Usually, a dc-dc or dc-ac converter is employed with an algorithm that control this later, this algorithm is called maximum power point tracker. The most well known MPPT algorithm is the Perturb and Observe (P\&O) [4]-[6], but this algorithm does not converge to the true maximum power point (MPP) [7], [8], and occurs some oscillations around the MPP [9]. The Incremental Conductance (INC) method [10]-[12], was considered as an improved P\&O method, until [4] proved that $\mathrm{P} \& \mathrm{O}$ and INC have equivalent performance. The step size in these two methods is defined by the conditions of the steady state calculation accuracy and the dynamic response time, which is a tradeoff [13]. Other classical methods also are reported in the literature such as fractional short-circuit current and fractional opencircuit voltage [14], but these methods also do not converge to the true MPP.

In the last few years, intelligent methods such as Fuzzy Logic [15], Neural Network [16] and Model Predictive Control (MPC) [3], were developed for better extraction of the maximum power from the PV arrays. The application of model predictive control on power electronics has started more than 20 years ago, but this was only for low switching frequency due to the limitations of microprocessors at that time [17]. In the last decade, the application of MPC in power electronics has increased considerably with the development of multitask and high-frequency microprocessors [18], [19], [20], and [21]. The MPC methods used in power electronics are classified into two main classes [18], [22]: the first one is Continuous Control Set MPC (CCS-MPC) and the second is Finite control set (FSC-MPC, hereafter referred to as FMPC), also known as discrete MPC. In CCS-MPC, the continuous output of the predictive controller is used for the generation of the switching state by employing a modulator. Whereas, the optimization in FMPC is done by using the discrete-time model of the system for the available switching states of the power converter, and the appropriate switching state will be applied in the next sampling period. FMPC offers the advantages of being easy to implement and applicable on nonlinear systems [23], but, its application on nonlinear systems is still limited by the dynamics of the system, contrary to CCS-MPC [24]. Recently, both MPC classes CCS-MPC such as presented in [24], [25] and FMPC [26], [3] have been used for tracking the MPP of the PV strings on the basis that they offer fast tracking during transient state and low power oscillations in the steady state compared with the classical methods.

MPC techniques provide a fast dynamic response with relatively high stability margin compared to classical control 
schemes, which make them more suited for MPPT of PV systems operating under fast changing atmospheric conditions [27]. However, there are still several open instability problems. Generally, it is the case when the operating point is not in the neighborhood of the tracked reference [28]. In [29], the authors proposed Lyapunov function for setting the cost function parameters based on Lyapunov stability theory to overcome this problem in power electronics generally. This solution can be used also on MPPT since it is not a particular case. The FMPC algorithm for power electronic converters is summarized in the following steps [30]: measure the currents and the voltages, predict the currents and the voltages for the next sampling time, evaluate the cost functions, select the switching states according to the minimized cost function and finally apply the selected switching states to the converter.

Concerning MPPTs, the cost function is calculated based on the predicted PV currents and/or the predicted PV voltages for all the switching states and the current and/or voltage reference. These references are usually calculated using $\mathrm{P} \& \mathrm{O}$ method such as in [26], [31] or INC as in [32], [33]. Eventually, the switching states corresponding to the reduced cost function will be applied. The application of MPC on MPPT in these papers is almost the same; the only difference is the converter topology: in [32] it has been applied on switched inductor quadratic boost converter, in [34] on boost converter, in [26] on flyback converter, in [31] on high gain multilevel dc-dc converter (multilevel boost converter), In [33] on grid tied multilevel boost converter, in [35] on ultrastep-up boost converter, and in [36] on sub-multilevel inverter. However, in [3], [37], and [38] MPC on MPPT has been applied otherwise. In [3] and [37] the predicted voltages and currents for only two states have been calculated, the first state for voltage reference larger than the PV voltage and the second state for voltage reference smaller than the PV voltage. In the following, the PV currents using a Digital Observer (DO) corresponding to these two voltage states are calculated. At the end, the voltage corresponding to the largest predicted power is chosen as a reference. The only difference between these two is that in [3] MPC has been applied on Z-Source inverter (ZSI), while in [37] boost converter is the target application. In [38], the proposed voltage oriented MPPT by [39] has been improved to current and voltage oriented MPPT using MPC, where the used topology was a boost converter. Note that, in all these proposed schemes, the prediction of the PV current and voltage is performed within a static PV curve for the actions that could be made on the duty duty cycle of the gating signal.

In the literature, it has been reported that the application of the MPC method on MPPTs compared to classical methods offers the following key advantages: robust control [36], a higher convergence speed under a changing environmental conditions [26], and less ripple during the steady state [38]. However, as shown later in this paper, the experimental results do not confirm with this statement, showing that the DO based MPC in fact produces higher ripple than $\mathrm{P} \& \mathrm{O}$ under low irradiance. Another important advantage of FMPC compared to the classical methods, is the application of the switching states directly from the control without using a modulation stage and without using a Proportional-Integral (PI) controller [18]. This latter, requires relatively a long time for the system to attain steady state operation. Also, increasing the response time between two successive reference outputs deteriorates the dynamic performance [40]. However, as found in the literature, the MPC method has three disadvantages. The first disadvantage is that it requires a microprocessor with high frequency and that, because it needs a small sampling time $(T s)$. The largest sampling time found in the literature is about $75 \mu \mathrm{s}$, which is reached by a calculation effort minimization algorithm done in [41]. The second one is that in some converters, it needs more than one voltage sensor and/or more than one current sensor, for example, in [33] authors used one current sensor and two voltage sensors. Also, the model parameter mismatch is another disadvantage, which influences the MPPT efficiency negatively as discussed and investigated in [3] and [42].

Tables I and II show the reported efficiencies of MPCMPPT by using different converter topologies under various constant irradiance levels and with model parameter mismatch. The efficiency of the MPPT can be improved enormously, by either improving the MPPT algorithm or the power converter [43]. Also the used PV simulator plays an important role in the assessment of the MPPT efficiency. Some PV simulators have some difficulties in adjusting the operating point compared to others, such as in [44]. Based on this, the results in these tables can not be compared to each others in term of control strategy. A detailed and thorough comparison of these proposed methods has not been carried out yet. In this regard, this paper has set out for detailed and fair comparison of these methods, by implementing them on the same test setup, under the same power range, and with the same updating rate.

DO based MPC-MPPT (DMPC-MPPT) operation principle also is based on the discrete time model, and the cost function minimization; therefore, it can be classified into discrete MPC-MPPT as well. This class is the one described and analyzed in this paper. The choice of this class has been made on the basis that it is the most relevant, cited, and published compared to other predictive control MPPTs.

This paper is organized in the following way: Section II shows the operational principles of both FMPC-MPPT and DMPC-MPPT. Section III presents examples of discrete MPC on a number of power converter topologies. Section IV explains in detail the simulation environment, experimental

TABLE I

REPORTED EFFICIENCIES (\%) OF MPC-MPPT USING DIFFERENT CONVERTERS UNDER VARIOUS CONSTANT IRRADIANCE LEVELS

\begin{tabular}{|c|c|c|c|c|c|c|}
\hline \multirow[b]{2}{*}{$\begin{array}{c}\text { Power Converter } \\
\text { Type }\end{array}$} & \multirow{2}{*}{$\begin{array}{l}\text { MPC-MPPT } \\
\text { Type }\end{array}$} & \multicolumn{4}{|c|}{ Solar irradiance } & \multirow[b]{2}{*}{$\begin{array}{l}\text { Average } \\
\text { Efficiency }\end{array}$} \\
\hline & & $\begin{array}{l}1000 \\
\mathrm{~W} / \mathrm{m}^{2}\end{array}$ & $\begin{array}{c}750 \\
\mathrm{~W} / \mathrm{m}^{2}\end{array}$ & $\begin{array}{c}500 \\
\mathrm{~W} / \mathrm{m}^{2}\end{array}$ & $\begin{array}{c}250 \\
\mathrm{~W} / \mathrm{m}^{2}\end{array}$ & \\
\hline Flyback [7] & $\begin{array}{l}\text { FMPC-MPPT } \\
\quad(\mathrm{P \& O})\end{array}$ & 99.60 & 99.95 & 99.71 & 99.70 & 99.74 \\
\hline $\begin{array}{c}\text { Z-Source inverter } \\
{[3]}\end{array}$ & DMPC- MPPT & 99.24 & 99.07 & 99.68 & 99.58 & 99.39 \\
\hline Boost [38] & $\begin{array}{l}\text { Oriented Voltage } \\
\text { and Current }\end{array}$ & \multicolumn{5}{|c|}{ No Data provided } \\
\hline $\begin{array}{l}\text { Multilevel Boost } \\
\qquad[45]\end{array}$ & $\begin{array}{c}\text { FMPC-MPPT } \\
(\mathrm{P} \& \mathrm{O})\end{array}$ & \multicolumn{5}{|c|}{ No Data provided } \\
\hline $\begin{array}{l}\text { Sensorless } \\
\text { Flyback [42] }\end{array}$ & $\begin{array}{l}\text { FMPC-MPPT } \\
\text { (INC) }\end{array}$ & 99.35 & 99.45 & 99.95 & 99.90 & 99.66 \\
\hline $\begin{array}{l}\text { Boost [34] } \\
\text { (simulation) }\end{array}$ & $\begin{array}{l}\text { FMPC-MPPT } \\
\text { (INC) }\end{array}$ & \multicolumn{4}{|c|}{ No Data provided } & 99.86 \\
\hline
\end{tabular}


TABLE II

REPORTED EFFICIENCIES (\%) OF MPC-MPPT USING DIFFERENT CONVERTERS WITH MODEL PARAMETER MISMATCH

\begin{tabular}{|c|c|c|c|c|}
\hline \multirow{2}{*}{$\begin{array}{l}\text { Power } \\
\text { Converter } \\
\text { Type } \\
\end{array}$} & \multirow{2}{*}{$\begin{array}{l}\text { MPC-MPPT } \\
\text { Type }\end{array}$} & \multicolumn{2}{|c|}{ Parameters Mismatch } & \multirow{2}{*}{$\begin{array}{l}\text { Average } \\
\text { Efficiency }\end{array}$} \\
\hline & & $-30 \%-15 \%$ & $0 \%+15 \%+30 \%$ & \\
\hline Flyback [7] & $\begin{array}{l}\text { FMPC-MPPT } \\
\quad(\mathrm{P \& O})\end{array}$ & \multicolumn{3}{|c|}{ No Data provided } \\
\hline $\begin{array}{l}\text { Z-Source } \\
\text { inverter [3] }\end{array}$ & DMPC-MPPT & $98.30 \quad 99.00$ & $\begin{array}{lll}99.25 & 99.20 & 98.90\end{array}$ & 98.93 \\
\hline Boost [38] & $\begin{array}{l}\text { Oriented Voltage } \\
\text { and Current }\end{array}$ & \multicolumn{3}{|c|}{ No Data provided } \\
\hline $\begin{array}{l}\text { Multilevel } \\
\text { Boost [45] }\end{array}$ & $\begin{array}{l}\text { FMPC-MPPT } \\
\quad(\mathrm{P \& O})\end{array}$ & \multicolumn{3}{|c|}{ No Data provided } \\
\hline $\begin{array}{l}\text { Sensorless } \\
\text { Flyback [42] }\end{array}$ & $\begin{array}{l}\text { FMPC-MPPT } \\
\text { (INC) }\end{array}$ & $99.15 \quad 99.85$ & $\begin{array}{lll}99.95 & 99.85 & 99.45\end{array}$ & 99.65 \\
\hline Boost [34] & $\begin{array}{l}\text { FMPC-MPPT } \\
\text { (INC) }\end{array}$ & \multicolumn{3}{|c|}{ No Data provided } \\
\hline
\end{tabular}

setup, and the test conditions. Section V shows the simulation and experimental results followed by a discussion. And in the final section (section VI), a conclusion of this work is presented.

\section{MODEL-PREDICTIVE-CONTROL BASED MPPT}

Predictive control denotes to a vast class of controllers which has been used in power electronics. All these controllers have been used for pursuing the MPP as well [3], [7], [42], and [46]-[49]. In this paper, we propose that these controllers are classified into four major types as sketched in Fig. 1. The control action in trajectory based is performed by making the controlled variable track a predefined trajectory. In deadbeat control, the error is forced to be zero for the next sampling instant by the optimal actuation. The feature of hysteresisbased MPPT, is to maintain the controlled variable within the barriers of a hysteresis area. The optimization criterion is based on the minimization of a cost function in both continuous and discrete MPC-MPPT. Continuous MPC-MPPT is based on the continuous-time model, where the prediction model is elaborated using Taylor series expansion. Discrete MPC-MPPT is explained in details in the following subsections.

\section{A. Finite Control Set Model Predictive Control-based MPPT}

FMPC has been used as a very powerful method to control the electrical energy employing power converters [50]. FMPC is easy to apply and has the ability to predict the behavior of the controlled variable by $N$ horizon length ahead, even in the existence of nonlinearities. In addition, it can avoid the use of

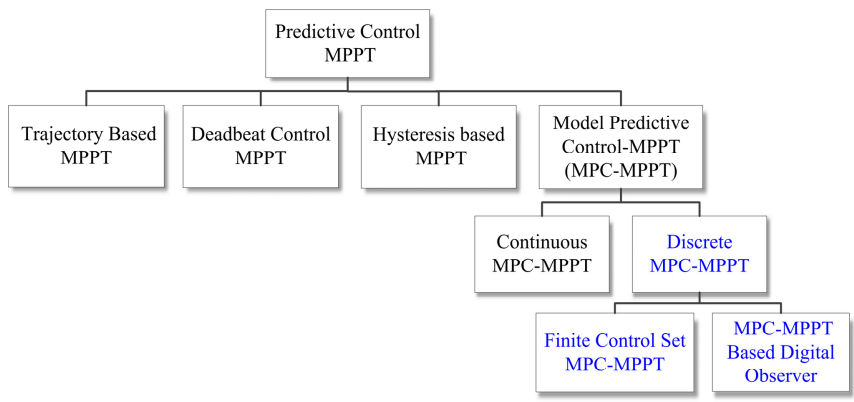

Fig. 1. A classification of Predictive Control based MPPT methods.

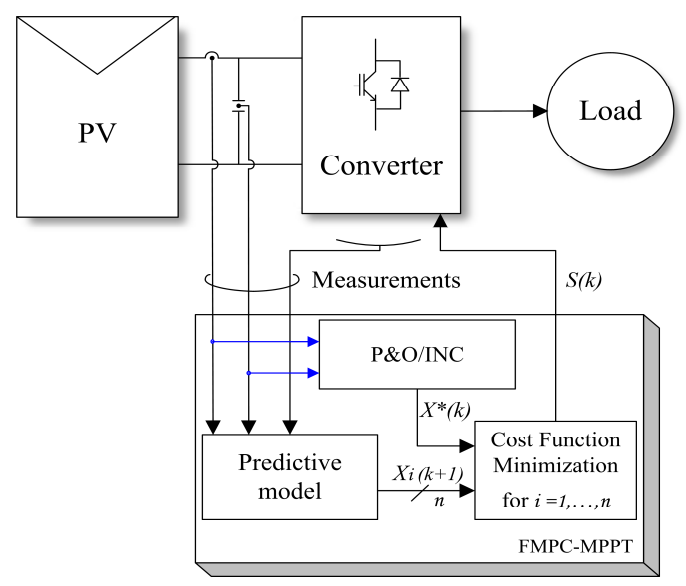

Fig. 2. General control block diagram of FMPC used for tracking the MPP.

PI controllers and the whole modulation stage. The horizon length $N$, is the prediction length as function of the sample time. In general, using a larger horizon length for the implementation of FMPC produces better performance [22], and subsequently more accurate tracking of the provided reference (MPP). However, the computation complexity increases exponentially with the increase of the horizon length. This increase imposes the designer to tradeoff online computational effort versus MPP tracking performance. Generally, FMPC provides excellent performance by using small values of horizon length. In this paper, the horizon length $N=1$, which means the predictions are done by one sample time ahead as shown in Fig. 3. The aim of using this modification on MPPT is for both decrease the response time to achieve the MPP under variable meteorological conditions. And also, to operate with fewer oscillations under constant solar irradiation and temperature.

The general control block diagram of a FMPC-MPPT method and the operation principle are illustrated in Fig. 2 and Fig. 3, respectively. The first step is to measure the system variables. The second step is to calculate the predicted

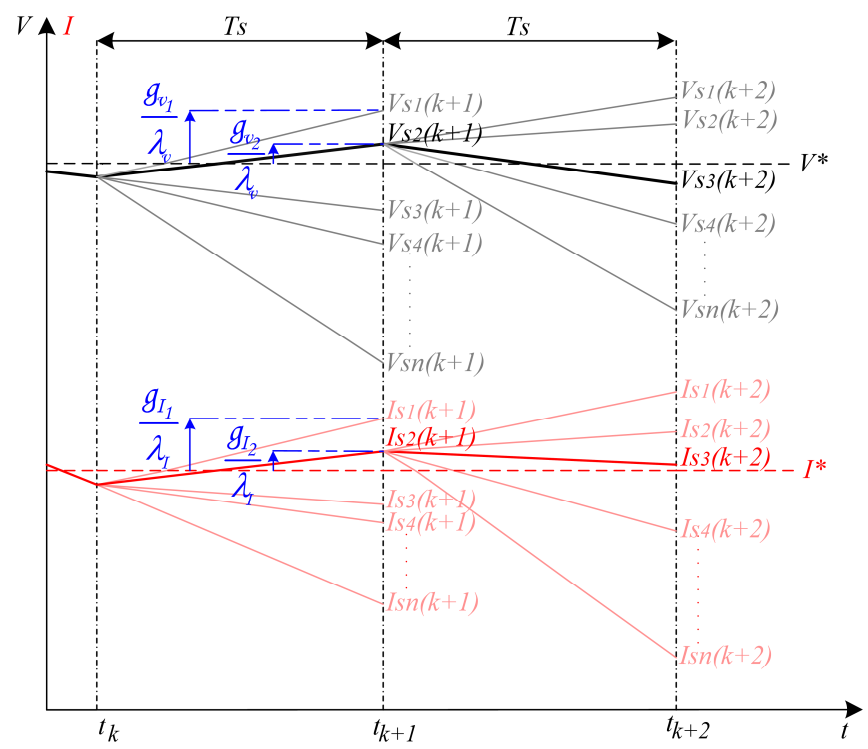

Fig. 3. The operation principle of a FMPC method on power electronics. 


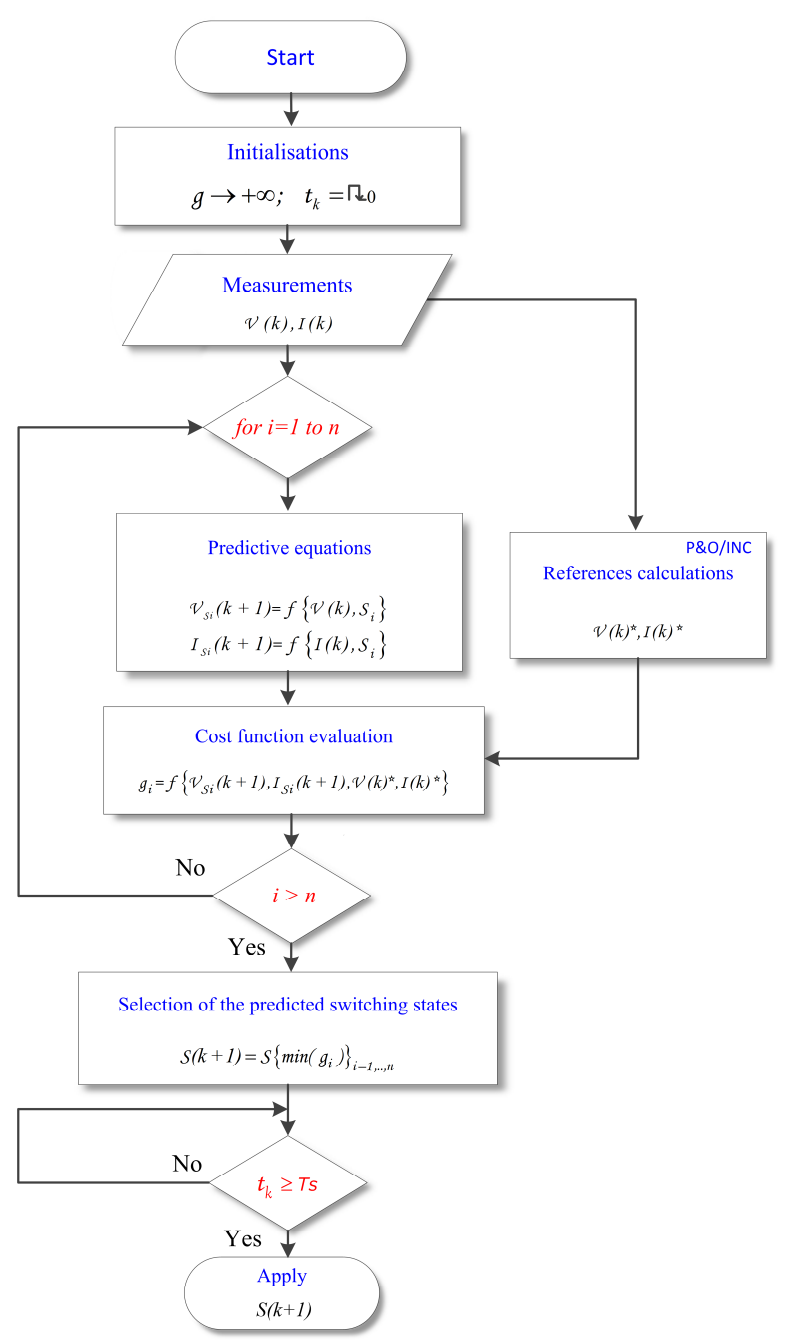

Fig. 4. A Flowchart of the general Finite control set MPC-based MPPT.

variables based on the extracted equations from the system and the measured data. This calculation should be for all the possible switching states (voltage vectors) as shown in Fig. 3 and Fig. 4. The next step is to minimize the cost function based on the predicted variables and their references. In a case of MPPT system, the variables are the PV current and voltage. Hence, the measurements consider the PV current $I(k)(k$ indicates the current sample time) and voltage $\mathcal{V}(k)$ and the variables that are included in the predictive equations.

The predicted variables should be the predicted PV currents $I_{S i}(k+1)$ and voltages $V_{S i}(k+1)$ for all the possible voltage vectors $(k+1$ indicates the next sample time). The cost function is minimized based on these predictions and their predicted references $V^{*}(k+1)$ and $I^{*}(k+1)$. Usually, the sampling time is in range of micro-seconds; thus, it is assumed that the predicted reference variable is equal to the instantaneous reference variable $X^{*}(k+1)=X^{*}(k)$ [22]. Generally, The cost function used for tracking the MPP is written as follows:

$$
g_{i\{1, \ldots, n\}}=\lambda_{v} \cdot\left|\mathcal{V}_{S i}(k+1)-\mathcal{V}^{*}\right|+\lambda_{I} \cdot\left|I_{S i}(k+1)-I^{*}\right|
$$

where $\lambda_{I}, \lambda_{v}$ are the weighting factors, $g$ is the cost function, $S i$ is the switching state, and $n$ is the number of the possible switching states $(n=8$, in a case of a classical 3 phase 2 level
Voltage Source Inverter). Until now there is no exact model for the calculation of the weighting factors [18], indeed, they are still defined by empirical tests. The reference variables are obtained from another algorithm (For example, from $\mathrm{P} \& \mathrm{O}$ or INC algorithm). Since the time of executing the algorithm is less than $T s$, the one before last step is to wait until the time from the previous application of the switching state $\left(t_{k}\right)$ reach $T s$, as shown in Fig. 4. Eventually, the application of the switching state $S(k)$ corresponding to the evaluated cost function.

\section{B. Digital observer MPPT-based Model Predictive Control}

Since DMPC emloys the PV characteristic for the construction of the predictive model. It has been used only for tracking the MPP, contrary to FMPC which has been used in many applications such as motor control [51], [52], tracking the MPP in renewable energy systems, electrical power quality improvement,...etc. DMPC-MPPT tracks the MPP by sliding the PV voltage to the voltage that makes the PV string generate its maximum power $\left(\mathrm{V}_{\mathrm{MPP}}\right)$. Fig. 6 shows the flowchart of the general DMPC-MPPT, such as $x$ is the PV voltage and $y$ is the PV current in case of voltage control, while in the other way around for current control.

The first step is the calculation of the step size $\Delta x(\Delta V$, voltage control is used in this section) by estimating the predicted average PV voltage, such as in [3]. Also, some examples of the estimation of the step size are elaborated in section III. However, as described in [37], a fixed voltage step size could also be set.

The second step consists on the calculation of the predicted PV voltages, which are defined as the difference between the PV voltage and the step size for the first case, and the addition of the PV voltage and the step size for the second case.

$$
V_{p v}(k+1)_{\{1,2\}}=V_{p v}(k) \pm \Delta V
$$

The third step consists on the calculation of the predicted PV currents by means of the DO [3], [37]. The DO models the PV array as two series elements $V_{e q}$ and $R_{e q}$ as shown in Fig. 5(b). The DO generates the values of these elements in order to allow the algorithm to calculate the predicted PV current corresponding to a given PV voltage. These elements are calculated based on $V_{p v}(k-1)$ and $I_{p v}(k-1)$, which are the PV voltage and current measured at the previous sampling time, respectively. Next, these elements will be substituted into a straight line equation (3), that is obtained by the application of Kirchoff's voltage law on the equivalent PV module circuit.

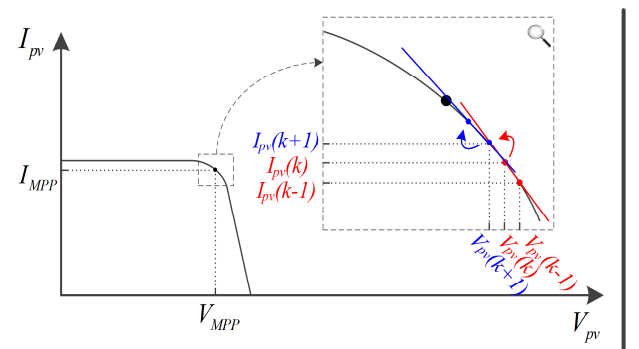

(a)

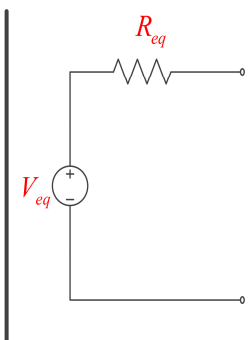

(b)
Fig. 5. (a) Extrapolation of the predicted PV current based on the predicted PV voltage and the straight line equation, (b) PV module equivalent circuit model used for the prediction of the PV string power. 


$$
\begin{gathered}
V_{e q}(k)=V_{p v}(k)+R_{e q}(k) \cdot I_{p v}(k) \\
R_{e q}(k)=-\frac{V_{p v}(k-1)-V_{p v}(k)}{I_{p v}(k-1)-I_{p v}(k)}
\end{gathered}
$$

The shifting increment is small, that implies that the straight line used for the prediction is small. Hence, the predicted PV current $I_{p v}(k+1)$ interpolated by this straight line equation will be on the PV curve as shown in Fig. 5(a).

The fourth step is the evaluation of the cost function, that one is described as the difference between the predicted PV power " $P_{p v}(k+1)_{\{1,2\}}=V_{p v}(k+1)_{\{1,2\} .} I_{p v}(k+1)_{\{1,2\} "}$ " and the PV power at the present sampling instant, which can be written in the following form:

$$
g_{\{1,2\}}=P_{p v}(k+1)_{\{1,2\}}-P_{p v}(k)
$$

Finally, the application of the predicted PV voltage $V_{p v}(k+1)$ corresponding to the chosen cost function. Hence, contrary to FMPC, a PI controller and a modulation stage are required in this method.

\section{EXAMPles of Discrete Model Predictive CONTROL- MPPT ON SOME POWER CONVERTER TOPOLOGIES}

In order to give a comprehensive concept of discrete MPCMPPT methods already described in the previous section, and

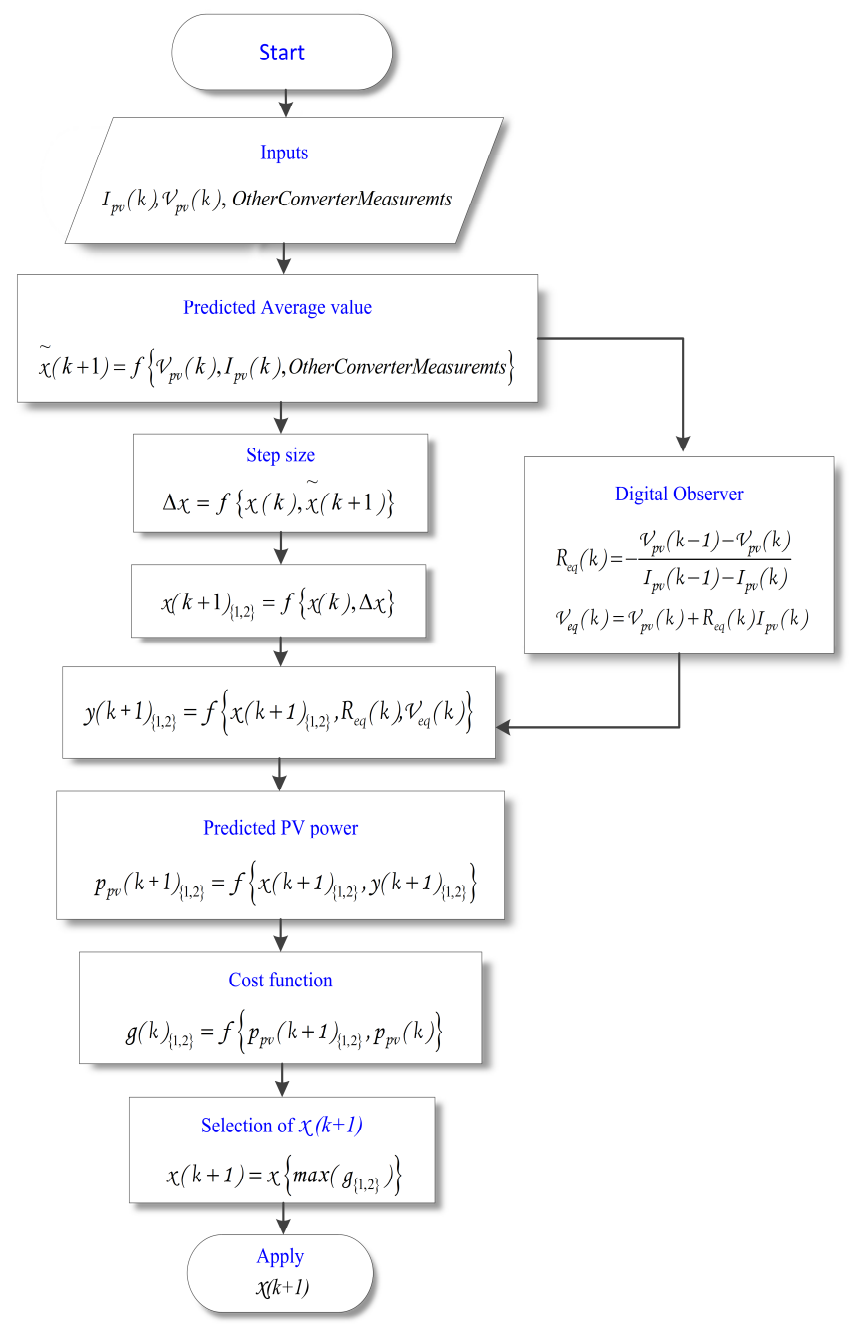

Fig. 6. A Flowchart of the general DMPC-MPPT.

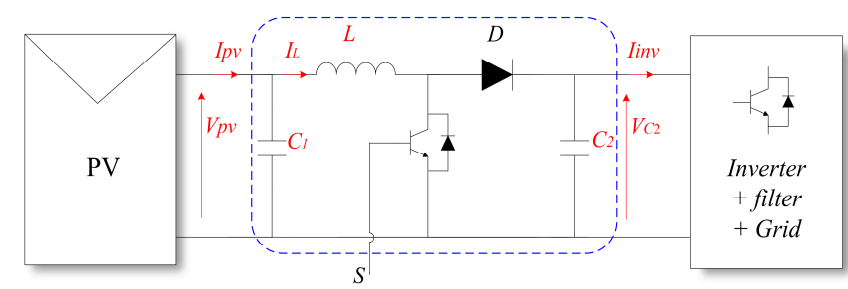

Fig. 7. Simplified schematic of the overall grid connected PV system configuration using dc-dc boost converter for withdrawing the maximum power.

since the application of FMPC-MPPT and DMPC-MPPT substantially related to the converter topology, this section has been devoted to the presentation of some examples of these methods on some power converter topologies.

\section{A. DC-DC Boost Converter}

1) Finite Control Set MPC-based MPPT on boost converter: A flowchart of FMPC-MPPT used to control the boost converter can be performed by following the procedure of the flowchart presented in Fig. 4. Where the aim of this control is to withdraw the maximum power from the PV array under any environmental conditions. The first step of FMPCMPPT application procedure is the extraction of the system equations. By applying Kirchoff's voltage law on Fig. 7, the continuous-time expressions of the boost converter for the two states can be found as follows:

$$
\left\{\begin{array}{l}
L \frac{d I_{L}}{d t}=V_{p v} \\
C_{2} \frac{d V_{C 2}}{d t}=-I_{i n v}
\end{array} \quad ; \text { for } S=1\right.
$$

and:

$$
\left\{\begin{array}{l}
L \frac{d I_{L}}{d t}=V_{p v}+V_{C 2} \\
C_{2} \frac{d V_{C 2}}{d t}=I_{p v}-I_{i n v}
\end{array} \quad ; \text { for } S=0\right.
$$

where $S=1$ and $S=0$ denote to switch $O N$ and switch $O F F$ states, respectively. Generally, the discrete-time model is obtained by using Euler's forward-difference law, which can be written as:

$$
\frac{d x}{d t} \approx \frac{x(k+1)-x(k)}{T s}
$$

The application of Euler's law on the boost switch $O N$ equations yields:

$$
\left\{\begin{array}{l}
I_{L}(k+1)=\frac{T s}{L} V_{p v}(k)+I_{L}(k) \\
V_{C 2}(k+1)=-\frac{T s}{C_{2}} I_{i n v}(k)+V_{C 2}(k)
\end{array}\right.
$$

The discrete-time model of the boost during switch OFF state was found similarly, as:

$$
\left\{\begin{array}{l}
I_{L}(k+1)=\frac{T s}{L}\left(V_{p v}(k)+V_{C 2}(k)\right)+I_{L}(k) \\
V_{C 2}(k+1)=\frac{T s}{C_{2}}\left(I_{p v}(k)-I_{i n v}(k)\right)+V_{C 2}(k)
\end{array}\right.
$$

The average value of the current through the capacitor $C_{1}$ is zero. Thus, the average current through the inductor $L$ is equal to the average value of the PV current. Therefore, The 
estimated value of the PV current in the next sampling time can be expressed based on (9) and (10).

The fact that:

$$
V_{p v}(k+1)=(1-D) \cdot V_{C 2}(k+1)
$$

the predicted PV voltages can be obtained by using (9) and (10). Such as $D$ is the duty ratio. Now, the cost function can be minimized using the following equation (12) based on these predicted variables and their references

$$
g_{\{0,1\}}=\lambda_{I} \cdot\left|I_{L}(k+1)_{\{0,1\}}-I^{*}\right|+\lambda_{v} \cdot\left|V_{p v}(k+1)_{\{0,1\}}-V^{*}\right|
$$

The one before last step is to wait until $t_{k}$ reaches $T s$. At that moment, the switching state corresponding to the minimized cost function is ready to be applied directly to the converter.

2) Digital observer MPC-based MPPT on boost converter: Fig. 6 illustrates the flowchart of DMPC-MPPT algorithm that can be used to control the boost converter. This control is performed by using the aforementioned steps. In this subsection, current control is used, and the current increment is chosen to be variable. This latter is described as the absolute difference between the average predicted PV current and the instantaneous PV current, which can be written as follows:

$$
\Delta I=\left|\tilde{I}_{L}(k+1)-I_{p v}(k)\right|
$$

The average predicted PV current is calculated by using the predicted current through the inductor in both cases switch $O N$ (9) and switch OFF (10) multiplied by the switching state:

$$
\tilde{I}_{L}(k+1)=I_{L 1}(k+1) \cdot S(k)+I_{L 0}(k+1) \cdot(1-S(k))
$$

Once the predicted PV currents " $I_{p v}(k+1)_{\{1,2\}}=I_{p v}(k) \pm \Delta I$ " are calculated, the DO will determine the predicted PV voltages, and the cost function can be calculated based on these predictions using (5). A PI controller is used to minimize the error between the predicted PV voltage matching the evaluated cost function and the PV voltage at the current sampling period. Then, the output of this controller is used to generate the pulses for the control of the boost converter through a modulator.

\section{B. Z-Source inverter}

The Z-source inverter has been introduced in 2003 [53]. Since then, the family of ZSI has been used in a wide range of power conversion as an interface between different types of sources and loads (dc-dc, ac-dc, dc-ac, and ac-ac). Contrary to the classical inverter, among its characteristics, is that it has a wide range of output voltage, in fact, it can step-up and stepdown the output voltage. In addition, the upper and lower power switches of each leg can be triggered simultaneously without any risk of damage [53]. This latter case is named as Shoot-Through (ST) state (Fig. 9(a)). As found in the literature, there are three modulation strategies of ZSI: SimpleBoost modulation [53], Constant-Boost modulation [54], and Maximum-Boost modulation [55]. In this paper, Simple-Boost modulation is used for the generation of the switching signals.

Equation (15) shows the rapport between the ac-side voltage and the PV side voltage:

$$
M . B=\frac{\hat{V}_{i n v}}{V_{p v}}=B_{B}
$$

where $B_{B}$ is the Buck-Boost factor, $M$ is the modulation index, $\widehat{V}_{i n v}$ is the ac-side peak voltage, and $B$ is the boosting factor. Being $D_{S T}$ the ST duty ratio, the relation between the boosting factor and the modulation index can be expressed in the following form:

$$
B=\frac{1}{2-1 / M}=\frac{1}{1-2 D_{S T}}
$$

1) Finite Control Set MPC-based MPPT on Z-Source inverter: The determination of the cost function is a key part of the MPC scheme, since it is defined by the variables that needs to be controlled. In a single stage grid-connected PV system, one of the controlled variables is the injected current to the grid, which must be in phase and has the same frequency as the grid voltage. Moreover, the Total Harmonic Distortion (THD) of the current should respect the values prescribed by the IEEE 519 Standards. The second variable is the PV string voltage, that should be shifted to the target voltage at which the PV panel should work at its maximum power, whatever the meteorological conditions are present. Therefore, the cost function can be defined as follows:

$$
g_{i}=\lambda_{I}\left|I_{L I_{i}}(k+1)-I^{*}\right|+\lambda_{v}\left|V_{p v_{i}}(k+1)-V^{*}\right|+\lambda_{G}\left|I_{G_{i}}(k+1)-I_{G} *\right|
$$

where $I_{L_{1}}(k+1)$ and $V_{C l}(k+1)$ are the predicted current through the inductor $L_{l}$ and the predicted voltage at the terminals of the capacitor $C_{l}$, respectively. Such as, the relationship between $V_{C l}(k+1)$ and the predicted PV voltage is as follows:

$$
V_{p v_{i}}(k+1)=\frac{2}{1+B} V_{C 1 i}(k+1)
$$

The purpose of including $I_{L_{1}}(k+1)$ and $V_{C I}(k+1)$ in the cost function is for shifting the PV voltage to $V_{M P P} . I_{G}(k+1)$ is the predicted current injected to the grid, which is used in the cost function to fulfill the conditions of the injected current based on a given grid current $I_{G}{ }^{*}$ (Fig. 3). In order to define the predicted variables in the first and the second term of the cost function, the model of ZSI in discrete-time domain is needed. During the Non-ST state, the discretized equations of the ZSI are as follows [3]:

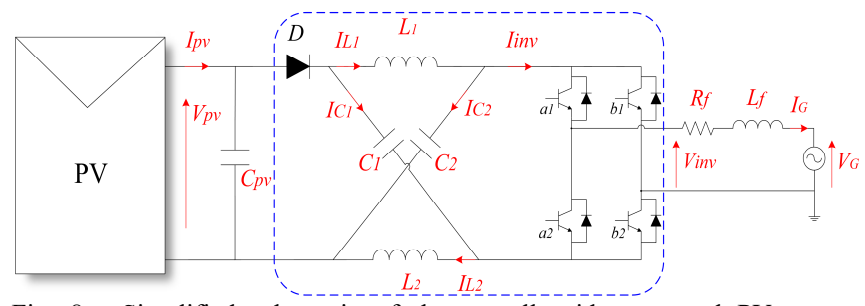

Fig. 8. Simplified schematic of the overall grid connected PV system configuration using Z-source inverter.

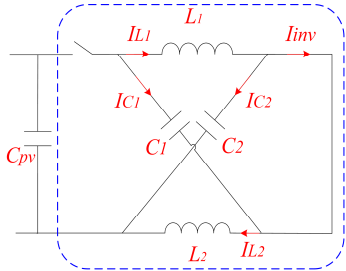

(a)

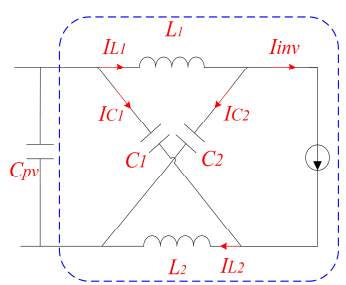

(b)
Fig. 9. (a) ZSI equivalent circuit in a Shoot-Through state, (b) ZSI equivalent circuit in a Non-Shoot-Through state. 


$$
\left\{\begin{array}{l}
I_{L 1}(k+1)=I_{L 1}(k)+\frac{T S}{L_{1}}\left(V_{p v}(k)-V_{C 1}(k)-R_{L 1} I_{L 1}(k)\right) \\
V_{C 1}(k+1)=V_{C 1}(k)+\frac{T s}{C_{1}}\left(I_{L 1}(k+1)-I_{i n v}(k+1)\right)
\end{array}\right.
$$

whereas the ST state, the discrete-time model is formulated as:

$$
\left\{\begin{array}{c}
I_{L 1}(k+1)=I_{L 1}(k)+\frac{T s}{L_{1}}\left(V_{C 1}(k)-R_{L 1} I_{L 1}(k)\right) \\
V_{C 1}(k+1)=V_{C 1}(k)-\frac{T s}{C_{1}} I_{L 1}(k+1) \\
I_{i n v}(k+1)=I_{G}(k) \cdot\left(S_{a}(k)-S_{b}(k)\right)
\end{array}\right.
$$

where $S_{a}(k)$ and $S_{b}(k)$ are the instantaneous switching states, $R_{L 1}$ the internal resistance of the inductor $L_{1}$, and $I_{i n v}(k+1)$ is the current going through the inverter in the next sampling period. In order to calculate the predicted variable in the third term of the cost function, the output inverter voltage $V_{i n v}$ as function of its current and filter parameters should be defined. The application of Kirchoff's law on the ac-side of the system (Fig. 8) provides the following vector differential expression:

$$
V_{i n v}=L_{f} \frac{d I_{G}}{d t}+R_{f} I_{G}+V_{G}
$$

The substitution of Euler's law into (22) gives the following discretized equation:

$$
I_{G}(k+1)=\left(1-\frac{R_{f}}{L_{f}} T s\right) I_{G}(k)+\left(V_{i n v}(k+1)-V_{G}(k)\right) \frac{T s}{L_{f}}
$$

where $V_{\text {inv }}(k+1)$ is the inverter voltage vector in the next sampling instant. Which can be defined as function of the switching states as follows:

$$
V_{\text {inv }}(k+1)=V_{p v}(k) \cdot B_{B} \cdot\left(S_{a}(k)-S_{b}(k)\right)
$$

The cost function should be calculated for all the available voltage vectors including ST state. The combination of both the ac-side voltage vector and the PV voltage that minimizes the cost function will be applied in the next sampling cycle. This combination is based on the selected weighting factors, which requires a certain sort of tradeoff among the objectives since it may not be easy to determine which one is the optimum.

2) Digital observer MPC-based MPPT on the Z-Source inverter: The voltage increment in this sub-section is recalculated at each sampling time. According to Fig. 6, to define the step size in case of ZSI, the predicted average PV voltage $\tilde{V}_{p v}(k+1)$ needs to be developed. This latter is calculated using the descritized equations of the converter during the ST state (19) and Non-ST states (20). By substituting (18) into (19) and (20), the average predicted PV voltage can be written as:

$$
\begin{gathered}
\tilde{V}_{p v}(k+1)=\frac{2}{1+B}\left(\left(V_{C 1}(k)+\frac{T s}{C_{1}}\left(I_{L 1}(k+1)-I_{i n v}(k+1)\right)\right) \cdot\left(1-D_{S T}\right)\right. \\
\left.+\left(V_{C 1}(k)-\frac{T S}{C_{1}} I_{L 1}(k)\right) \cdot D_{S T}\right)
\end{gathered}
$$

The voltage increment is defined as the difference between the current PV voltage and the predicted average PV voltage:

$$
\Delta V=\left|\tilde{V}_{p v}(k+1)-V_{p v}(k)\right|
$$

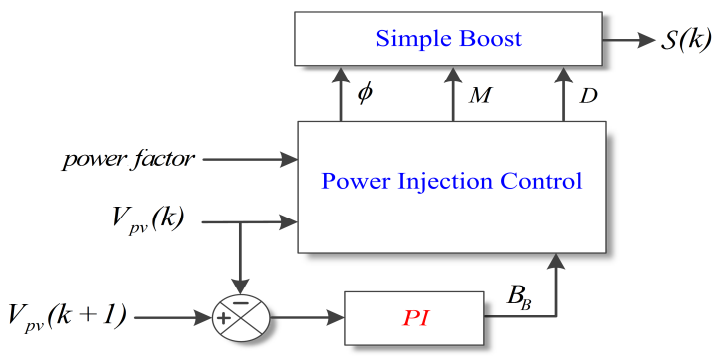

Fig. 10. The overall procedure of defining the switching state based on the predicted PV voltage, and the desired power factor.

The next step of DMPC-MPPT algorithm, is the calculation of the predicted PV voltages $V_{p v}(k+1)_{1}$ and $V_{p v}(k+1)_{2}$ by using (2). The predicted PV currents $I_{p v}(k+1)_{1}$ and $I_{p v}(k+1)_{2}$ can be calculated based on the predicted PV voltages using the DO. Hence, all the unknown variables of the cost function (5) are ready to be substituted, and the predicted PV voltage will be set based on the evaluated cost function as shown in Fig. 6. In this sub-section, it can be noted that the MPC is used only for tracking the MPP by defining the behavior of the PV power in the next sampling time $P_{p v}(k+1)$. The power injection control is done separately by using classical methods. Fig. 10 describes the overall procedure of defining the switching state based on the predicted PV voltage that needs to be applied at the next sampling time and the desired power factor, where, $D_{S T}$ and $M$ are expressed as follows [54], [55]:

$$
\left\{\begin{array}{lll}
D_{S T}=0, & M=B_{B} & ; \text { for } B_{B} \leq 1 \\
D_{S T}=1-M, & M=\frac{B_{B}}{2 \cdot B_{B}-1} ; \text { for } B_{B}>1
\end{array}\right.
$$

\section{Flyback Converter}

Flyback is the third converter used in this paper as an example and for the evaluation of discrete MPC-MPPT. This latter, has been already applied on flyback converter using FMPC-MPPT [26], but is it has not been thoroughly investigated. In the next two sub-sections, both FMPC-MPPT and DMPC-MPPT using a flyback converter are described.

1) Finite Control Set MPC-based MPPT on flyback converter: In a double stage grid-connected PV system, the tracking of the MPP is done apart by employing a dc-dc converter. Hence, the static cost function (1) can be used in this sub-section directly without any additional terms. In multiobjective control systems, and for more efficient references tracking, other works proposed the use of a dynamic cost function, in which the weighting factors are optimized

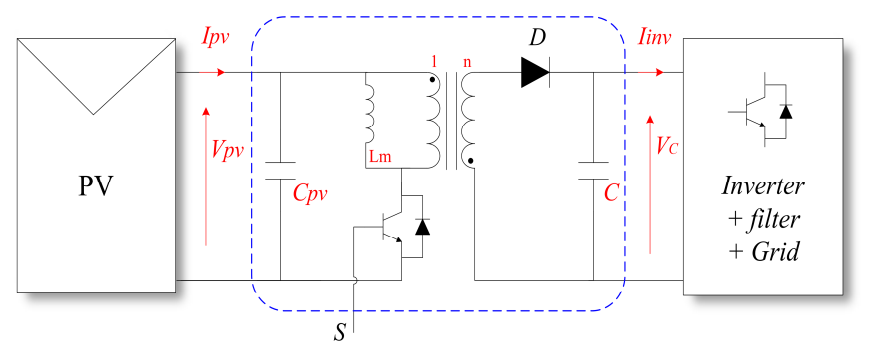

Fig. 11. Simplified schematic of the overall grid connected PV system configuration using flyback converter as an interface for tracking the MPP. 
online [56]. Within simplicity, MPC depends on the mathematical model of the variables that need to be predicted for each converter's possible operation state. The following equations can be obtained by the application of Euler's forward law on the dynamic model of the flyback converter (Fig. 11):

$$
\begin{cases}I_{p v}(k+1)=I_{p v}(k)+\frac{T S}{L m} V_{p v}(k) & \\ V_{C}(k+1)=V_{C}(k)+\frac{T S}{C} I_{i n v}(k) & ; \text { for } S=1\end{cases}
$$

and:

$$
\left\{\begin{array}{l}
I_{p v}(k+1)=I_{p v}(k)-\frac{T s}{L m \cdot n} V_{C}(k) \\
V_{C}(k+1)=V_{C}(k)+\frac{T S}{C}\left(\frac{1}{n} I_{p v}(k)-I_{i n v}(k)\right)
\end{array} \quad ; \text { for } S=0\right.
$$

where the relationship between the output voltage of the flyback converter and the PV voltage is given by:

$$
V_{p v}(k+1)=V_{C}(k+1) \frac{1-D}{n \cdot D}
$$

Equation (28) and (29) are substituted into the cost function (1), and the switching action corresponding to the nearest predicted current/voltage to the current/voltage reference will be applied to the converter. A new switching state can be applied at every update instant and is maintained all along the update period. At the end of each updating period, the FMPC algorithm starts again, resulting in that named as receding horizon.

2) Digital observer MPC-based MPPT on flyback converter: By using the predicted variables in both cases switch $O N$ and switch $O F F$, the average predicted voltage $\widetilde{V}_{p v}(k+1)$ can be assessed. Which is deduced as function of the predicted PV voltage for the two operation states and the switching state at the current sampling cycle (31) [57]

$$
\begin{aligned}
\tilde{V}_{p v}(k+1)=\frac{1-D}{n \cdot D} & \left(\left(V_{C}(k)+\frac{T s}{C} I_{i n v}(k)\right) S(k)+\right. \\
& \left.\left(V_{C}(k)+\frac{T s}{C}\left(\frac{1}{n} I_{p v}(k)-I_{i n v}(k)\right)\right)(1-S(k))\right)
\end{aligned}
$$

The predicted PV voltages $V_{p v}(k+1)_{1}$ and $V_{p v}(k+1)_{2}$ and the voltage step size can be calculated based on (2) and (26), repectively. The DO is used in this sub-section for the calculation of the predicted PV currents $I_{p v}(k+1)_{1}$ and $I_{p v}(k+1)_{2}$ corresponding to the calculated predicted PV voltages. The cost function (5) will be calculated based on the predicted PV powers $P_{p v}(k+1)_{1}$ and $P_{p v}(k+1)_{2}$ and the PV power at the current sampling instant $P_{p v}(k)$. If $g_{1}$ is greater than $g_{2}$, then $V_{p v}(k+1)_{1}$ will be chosen as the next PV voltage, otherwise $V_{p v}(k+1)_{2}$ will be chosen as the next PV voltage as depicted in Fig. 6. And this, in order to choose the predicted PV voltage that leads to a greater power harvesting form the PV string in each sampling cycle. All it remains, is the control of the PV voltage on the chosen predicted PV voltage $V_{p v}(k+1)$ by using a classical voltage regulation loop, in which a PI controller is employed.

\section{SYSTEM DESCRIPTION}

To verify the theoretical analysis and to evaluate both FMPCMPPT and DMPC-MPPT methods, simulation models have been built with the configurations shown in Fig. 7, Fig. 8, and Fig. 11. These ideal simulations were validated further by an experimental implementation of the configuration illustrated in Fig. 7.

\section{A. Description of the Simulation-Environment}

The dynamic simulation was by using a developed mathematical model of the PV array and the data sheet of TOTAL ENERGY TE $600 \mathrm{PV}$ module to emulate the behavior of a real PV string. To simulate the configurations in Fig. 7 and Fig. 11. An accurate models of the boost and flyback converters have been employed for withdrawing the maximum power from the emulated PV strings and injecting it to the grid through a single phase inverter and an $L C L$ filter, where the total string voltage was set to $V_{M P P}=300 \mathrm{~V}$ and the power to $P_{M P P}=704 \mathrm{~W}$ under the standard meteorological conditions (STC, $1000 \mathrm{~W} / \mathrm{m}^{2}$ of solar irradiance and $25^{\circ} \mathrm{C}$ of temperature). Also, the configuration in Fig. 8 has been simulated, by connecting the ZSI to a PV string of $V_{M P P}=450 \mathrm{~V}$ and $P_{M P P}=1350 \mathrm{~W}$. The MPPT used for providing the references in case of implementing FMPC-MPPT is P\&O method, with a voltage increment of $\Delta V=1 \mathrm{~V}$ for the voltage reference and a current step size of $\Delta I=0.025 \mathrm{~A}$ for the current reference. The sampling time and the MPPT frequency were adjusted to $50 \mu \mathrm{s}$ and $40 \mathrm{~Hz}$, respectively.

\section{B. Description of the Experimental-Setup}

Fig. 12 shows the block scheme of the experimental setup, which considers the realization of the configuration shown in Fig. 7 in case of a standalone system. Where the used components were: an Agilent E4360A PV simulator with two channels, each channel provides up to $600-\mathrm{W}$ power $(120-\mathrm{V}$, 5.1-A), a 400-W prototype dc-dc boost converter, which has been made to extract the local maximum power of a real PV panel, and a resistive load. The PV simulator emulates the uploaded $I-V$ curve of a PV string with $P_{M P P}=122-\mathrm{W}$ at $V_{M P P}=25-\mathrm{V}$ under STC. The PV curve has been uploaded and updated in case of solar irradiance changes using Keysight commands through Matlab. The MPPT algorithms that control the boost have been implemented in Matlab/Simulink. Then, by using dSPACE real-time interface the program has been compiled and uploaded to dSPACE 1103 controller board. The MPPT used for providing the references in case of implementing FMPC-MPPT is $\mathrm{P} \& \mathrm{O}$ algorithm. The MPPT frequency was set to $25-\mathrm{Hz}$, with a voltage step size of $\Delta V=$ $0.25-\mathrm{V}$ for the voltage reference and a current step size of $\Delta I$ $=0.01-\mathrm{A}$ for the current reference. The model of the boost converter used in the simulation model is designed for grid connected system, but the one used in the experimental setup is a smaller one (400-W power), with smaller inductor compared to the one used in the simulation model. The ideal operation of this boost converter is at $35 \mathrm{kHz}$ switching frequency, which corresponds approximately to $30 \mu \mathrm{s}$ switching/sampling period.

\section{Static tests according to EN 50530 standard}

The static tests were done under seven defined solar irradiation levels. In each level, the inverter voltage was set to the minimum MPP voltage $\left(V_{\min }\right)$, the rated MPP voltage $\left(V_{r t d}\right)$, and the maximum MPP voltage $\left(V_{\max }\right)$. The static 
efficiency was calculated based on these tests using the European weighting factors as follows [58]:

$$
\begin{aligned}
\eta_{E U}= & 0.03 \cdot \eta_{05 \%}+0.06 \cdot \eta_{10 \%}+0.13 \cdot \eta_{20 \%}+ \\
& 0.10 \cdot \eta_{30 \%}+0.48 \cdot \eta_{50 \%}+0.20 \cdot \eta_{100 \%}
\end{aligned}
$$

As well as by California Energy Commission weighting factors (33):

$$
\begin{aligned}
\eta_{C E C}= & 0.04 \cdot \eta_{10 \%}+0.05 \cdot \eta_{20 \%}+0.12 \cdot \eta_{30 \%}+ \\
& 0.21 \cdot \eta_{50 \%}+0.53 \cdot \eta_{75 \%}+0.05 \cdot \eta_{100 \%}
\end{aligned}
$$

Such as, $\eta_{05 \%}$ denotes to the efficiency of the MPPT for a PV string working under $5 \%$ of the solar irradiation in standard conditions. At each irradiation level, the efficiency was calculated by the following expression:

$$
\eta=\frac{1}{P_{a v} \cdot T_{M}} \sum_{i=1}^{n} P_{p v} \cdot \Delta T
$$

where $P_{a v}$ is the available power in the PV string, $P_{p v}$ is the extracted power from the $\mathrm{PV}$ string, $T_{M}$ is the total measurement time, $\Delta T$ is the sampling period of the efficiency calculation loop, and $n$ is the total number of periods.

\section{D.Dynamic tests according to EN 50530 standard}

The dynamic efficiency was calculated by applying to the emulated PV string a trapezoidal irradiation profiles executed in two successive tests. Very low to medium test, in a range of $10 \%$ to $50 \%$ of the solar irradiance in STC. After a defined settling time, low to high irradiation test in a range of $30 \%$ to $100 \%$ of the solar irradiance in STC as shown in Fig. 13. Each

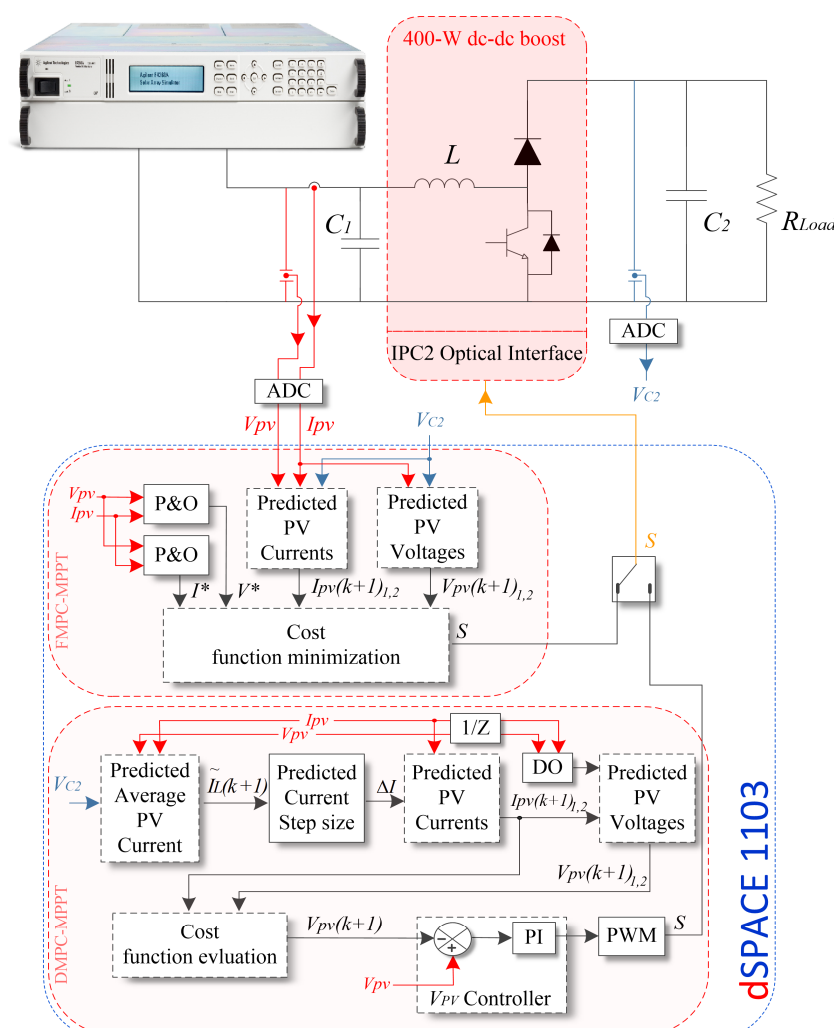

Fig. 12. Global diagram of the experimental test bench, and the main control structure of both discrete MPC-MPPT methods using boost converter.

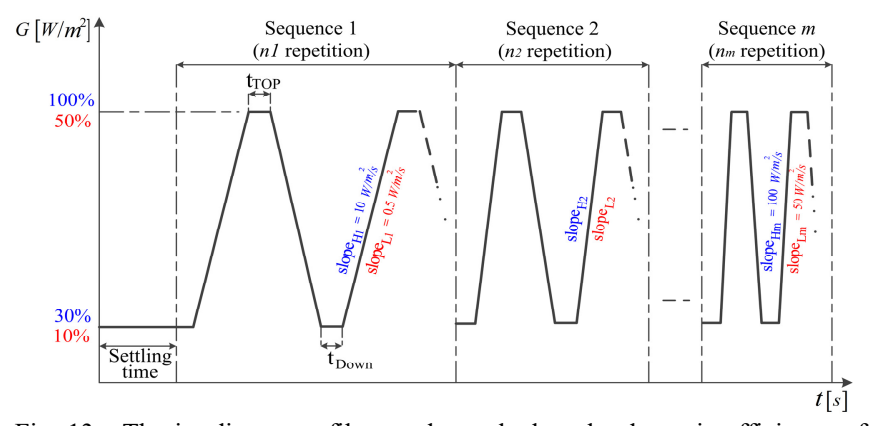

Fig. 13. The irradiance profiles used to calculate the dynamic efficiency of the MPPT, according to EN 50530 standard. The red and blue colors indicate to the solar irradiation ranges and slopes of very low to medium irradiance test and low to high solar irradiance test, respectively.

test was done in several defined sequences, and in each sequence, the irradiation profile has been repeated several defined times. The slope in the very low to medium irradiance test was varying from $0.5 \mathrm{~W} / \mathrm{m}^{2} / \mathrm{s}$ in the first sequence (slope $\left.{ }_{L 1}\right)$ up to $50 \mathrm{~W} / \mathrm{m}^{2} / \mathrm{s}$ in the last sequence $\left(\right.$ slope $_{L m}$ ). Whereas the slope in low to high irradiance test, was varying from $10 \mathrm{~W} / \mathrm{m}^{2} / \mathrm{s}$ in the first sequence $\left(\right.$ slope $\left._{H I}\right)$ up to $100 \mathrm{~W} / \mathrm{m}^{2} / \mathrm{s}$ in the last sequence (slope $\mathrm{Hm}_{\text {) }}$ [59]. In every separate repetition, the dynamic efficiency was calculated by using the following expression:

$$
\eta_{D y n, i}=\frac{1}{\sum_{j=1}^{n} P_{a v} \cdot \Delta T} \cdot \sum_{j=1}^{n} P_{p v} \cdot \Delta T
$$

Being $n_{m}$ the number of repetitions, the dynamic efficiency corresponding to EN50530 standard can be written as:

$$
\eta_{D y n}=\frac{1}{n_{m}} \sum_{i=1}^{n_{m}} \eta_{D y n, i}
$$

The aim of repeating the irradiation profiles in each sequence is not to estimate the average MPPT efficiency. These repetitions are by reason of calculating the efficiency of an MPPT integrated into the whole system under test [58]. Based on this, the simulation model was constructed to execute only one irradiation profile per sequence.

\section{E. Model parameter mismatch}

It is well known that the presence of modeling errors can affect MPC controllers. The mismatch between the real value of the parameter and the value that has been set in the mathematical model, causes to a deviated prediction of the controlled variable. This may lead to a wrong decision for the selection of the switching state when reaching a certain threshold of model parameter mismatch. This threshold varied according to the MPC control type and the power converter topology. For this purpose, we have performed several tests using the aforementioned converters. The values of the parameters were adjusted for different mismatch levels, in a range of $-30 \%$ to $+30 \%$. Note that these tests have been performed under the STC.

\section{RESUltS AND DisCUSSION}

\section{A. Simulation results}

For comparison purposes, $\mathrm{P} \& \mathrm{O}$ also has been implemented on the same system and tested under the static and dynamic 


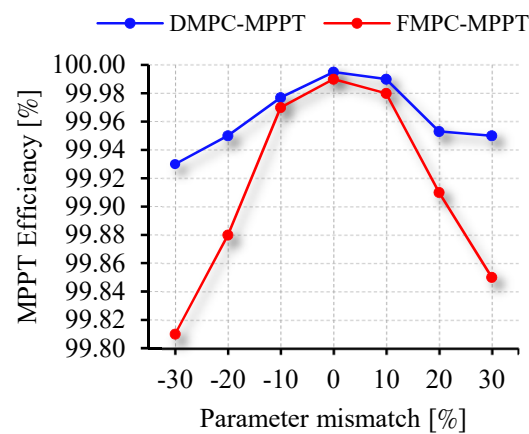

(a)

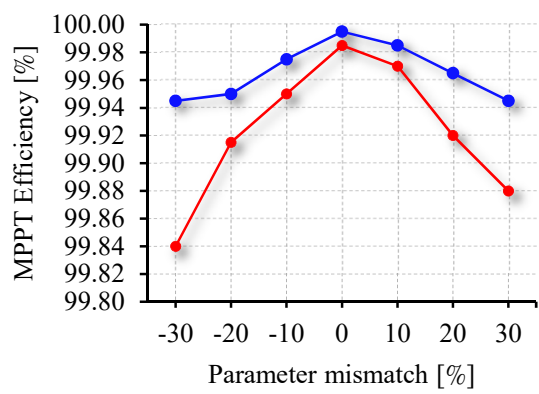

(b)

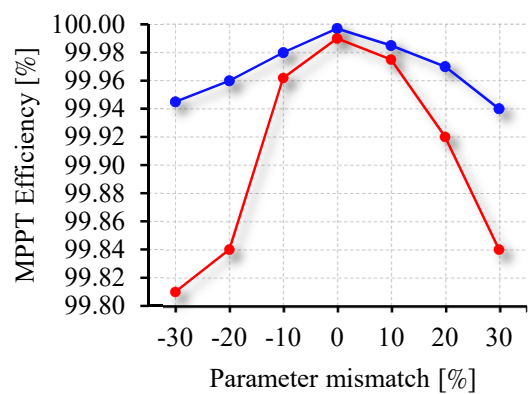

(c)

Fig. 14. Simulation results of FMPC-MPPT and DMPC-MPPT efficiencies under STC, and in case of model parameter mismatch using: (a) Boost converter " $L$ and $C_{2}$ ", (b) Z-source inverter " $C_{l}$ and $L_{l}$ ", and (c) Flyback converter " $C$ and $L_{m}$ ".

conditions. Tables III and IV show the efficiencies of P\&O, FMPC, and DMPC calculated by using both the European and California's formulas, respectively. Unlike the efficiency of the inverter, the efficiency of the MPPT normally is calculated with a resolution of two decimals [4]. It can be seen from these tables that the efficiencies of these methods are the same in some cases; extremely close in the other cases. With a maximum difference of $0.03 \%$. However, in only one case ( $\eta_{\text {Euro }}$ of Z-source inverter), DMPC shows a relatively better efficiency with a difference of $0.06 \%$ compared to other methods.

TABLE III

SiMULATION RESUlTS OF THE MPPT EFFICIENCY CALCULATED USING THE EUROPEAN FORMULA (\%)

\begin{tabular}{|c|c|c|c|c|}
\hline $\begin{array}{c}\text { Power } \\
\text { Converter }\end{array}$ & Voltage & $\mathrm{P} \& \mathrm{O}$ & $\begin{array}{l}\text { FMPC- } \\
\text { MPPT }\end{array}$ & $\begin{array}{l}\text { DMPC- } \\
\text { MPPT }\end{array}$ \\
\hline \multirow{4}{*}{ Boost } & $\mathrm{V}_{\mathrm{MPP}} \min$ & 99.81 & 99.80 & 99.83 \\
\hline & $\mathrm{V}_{\mathrm{MPP}}$ rated & 99.95 & 99.97 & 99.98 \\
\hline & VMPP_max & 99.93 & 99.96 & 99.95 \\
\hline & Average & 99.89 & 99.91 & 99.92 \\
\hline \multirow{4}{*}{$\begin{array}{l}\text { Z-source } \\
\text { inverter }\end{array}$} & $\mathrm{V}_{\mathrm{MPP}} \min$ & 99.92 & 99.83 & 99.95 \\
\hline & VMPP_rated & 99.91 & 99.93 & 99.96 \\
\hline & $\mathrm{V}_{\mathrm{MPP}}$ max & 99.88 & 99.95 & 99.97 \\
\hline & Average & 99.90 & 99.90 & 99.96 \\
\hline \multirow{4}{*}{ Flyback } & $\mathrm{V}_{\mathrm{MPP}_{-} \min }$ & 99.92 & 99.93 & 99.93 \\
\hline & $\mathrm{V}_{\mathrm{MPP}}$ rated & 99.92 & 99.94 & 99.94 \\
\hline & $\mathrm{V}_{\mathrm{MPP}}$ max & 99.89 & 99.91 & 99.92 \\
\hline & Average & 99.91 & 99.92 & 99.93 \\
\hline
\end{tabular}

TABLE IV

SIMULATION RESULTS OF THE MPPT EFFICIENCY CALCULATED USING CALIFORNIA'S FORMULA (\%)

\begin{tabular}{ccccc}
\hline \hline $\begin{array}{c}\text { Power } \\
\text { Converter }\end{array}$ & Voltage & P\&O & $\begin{array}{c}\text { FMPC- } \\
\text { MPPT }\end{array}$ & $\begin{array}{c}\text { DMPC- } \\
\text { MPPT }\end{array}$ \\
\hline \multirow{5}{*}{ Boost } & $\mathrm{V}_{\text {MPP_min }}$ & 99.87 & 99.87 & 99.91 \\
& $\mathrm{~V}_{\text {MPP_rated }}$ & 99.96 & 99.98 & 99.94 \\
& $\mathrm{~V}_{\mathrm{MPP} \text { max }}$ & 99.94 & 99.97 & 99.96 \\
& Average & 99.92 & 99.94 & 99.94 \\
& $\mathrm{~V}_{\mathrm{MPP} \text { min }}$ & 99.95 & 99.91 & 99.95 \\
Z-source & $\mathrm{V}_{\mathrm{MPP} \text { rated }}$ & 99.92 & 99.93 & 99.96 \\
& $\mathrm{~V}_{\mathrm{MPP} \text { max }}$ & 99.90 & 99.96 & 99.96 \\
& Average & 99.92 & 99.93 & 99.95 \\
& $\mathrm{~V}_{\mathrm{MPP} \text { min }}$ & 99.93 & 99.94 & 99.95 \\
Flyback & $\mathrm{V}_{\mathrm{MPP} \text { rated }}$ & 99.93 & 99.95 & 99.95 \\
& $\mathrm{~V}_{\mathrm{MPP} \text { max }}$ & 99.90 & 99.93 & 99.94 \\
& Average & 99.92 & 99.94 & 99.95 \\
\hline \hline
\end{tabular}

As can be seen from Table $\mathrm{V}$, there is a clear difference between P\&O and DMPC dynamic performances. DMPC has a better dynamic efficiency for all the converters. The minimum difference is $0.65 \%$, which corresponds to the flyback converter. Whereas the dynamic efficiency of FMPC is very close to the efficiency of $\mathrm{P} \& \mathrm{O}$ with a maximum difference of $0.12 \%$.

The results shown in Fig. 14(a), Fig. 14(b), and Fig. 14(c) were obtained where the system was working with model parameter inaccuracy. As observed from these figures, the efficiency of FMPC decreases to $99.80 \mathrm{~s} \%$ when the system is working with $\pm 30 \%$ model parameter mismatch. DMPC's efficiency decreases to $99.90 \mathrm{~s} \%$ when it is working with $\pm 30 \%$ parameter mismatch. It can be concluded that, FMPC-MPPT is the more influenced by the parameter mismatch, whereas DMPC-MPPT shows a robustness for this test. Also, it is worth mentioning that the overestimation of the parameters in all these converters is less influencing than their underestimation.

\section{B. Experimental results}

In order to confirm the results found by the simulation models, experimental tests have been carried out. Table VI summarizes both EN 50530 static and dynamic efficiencies using a boost converter in case of a standalone system (see Fig. 12). It can be seen from this table that the static efficiencies of FMPC-MPPT are very close to $\mathrm{P} \& \mathrm{O}$, showing a difference of $0.03 \%$ and $0.02 \%$ for $\eta_{\text {Euro }}$ and $\eta_{C E C}$, respectively, which is still within the statical range between

TABLE V

SIMULATION RESULTS OF THE MPPT EFFICIENCIES UNDER EN50530 STANDARDS DYNAMIC CONDITIONS (\%) AND TIME CONVERGENCE UNDER THE STC (S)

\begin{tabular}{|c|c|c|c|c|c|c|}
\hline \multirow{2}{*}{$\begin{array}{c}\text { Power } \\
\text { Converter }\end{array}$} & \multicolumn{3}{|c|}{$\eta_{D y n}$} & \multicolumn{3}{|c|}{ Time Convergence } \\
\hline & $\mathrm{P} \& \mathrm{O}$ & $\begin{array}{l}\text { FMPC- } \\
\text { MPPT }\end{array}$ & $\begin{array}{l}\text { DMPC- } \\
\text { MPPT }\end{array}$ & $\mathrm{P} \& \mathrm{O}$ & $\begin{array}{l}\text { FMPC- } \\
\text { MPPT }\end{array}$ & $\begin{array}{c}\text { DMPC- } \\
\text { MPPT }\end{array}$ \\
\hline Boost & 98.50 & 98.62 & 99.18 & 0.42 & 0.39 & 0.27 \\
\hline $\begin{array}{c}\text { Z-source } \\
\text { inverter }\end{array}$ & 98.11 & 98.23 & 99.03 & 0.36 & 0.31 & 0.26 \\
\hline Flyback & 98.37 & 98.48 & 99.02 & 0.25 & 0.26 & 0.13 \\
\hline
\end{tabular}


two successive tests. Regarding DMPC-MPPT static efficiencies, they are less than $\mathrm{P} \& \mathrm{O}$ static efficiencies, with a difference of $0.05 \%$ and $0.06 \%$ for $\eta_{\text {Euro }}$ and $\eta_{C E C}$, respectively. However, they are within the agreement of the outdoor results reported in [60].

Also, the difference between the dynamic efficiency of FMPC-MPPT and $\mathrm{P} \& \mathrm{O}$ is within the statical range between two successive tests. Whereas, there is a significant difference between the dynamic efficiency of DMPC-MPPT and the others. Therefore, some figures of some repetitions of these MPPTs working under EN50530 standard dynamic conditions are presented (Fig. 15 and Fig. 16). These figures are corresponding to repetitions from the last three sequences.

Again, it can be seen from these figures that FMPC-MPPT has the same behavior as P\&O, and FMPC-MPPT fails to pursue the MPP in the same sequences the $\mathrm{P} \& \mathrm{O}$ fails. Except in Fig. 15.(a) and Fig. 16.(b), FMPC-MPPT failed at first and then it converged to the MPP. DMPC-MPPT shows a better performance compared to FMPC-MPPT in this test. Actually, it did not fail for pursuing the MPP in all the sequences, except in the last sequence from very low to medium irradiance test (Fig. 15.(c)). Also it did not track the MPP well in the last sequence from low to high insolation test Fig. 16(c).

In this paper, only repetitions from the last three sequences from EN 50530 standard dynamic conditions have been presented, because $\mathrm{P} \& \mathrm{O}$ and FMPC-MPPT start fail to pursue
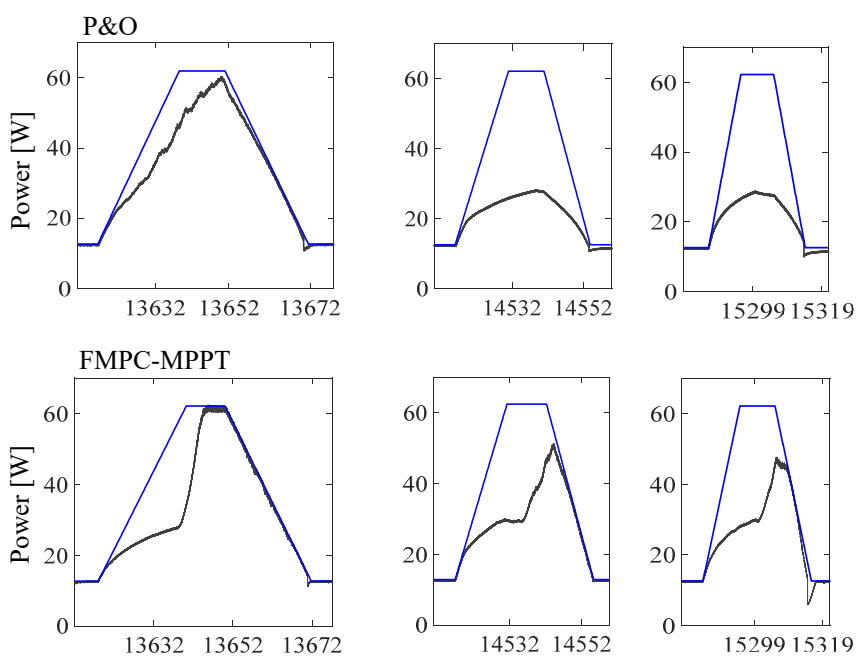

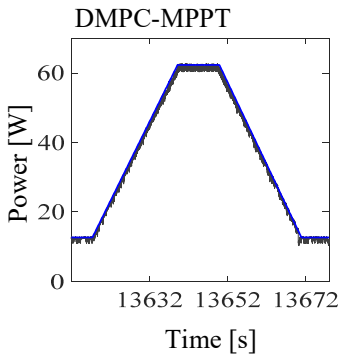

(a)

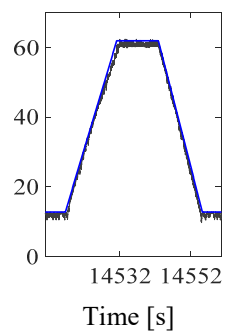

(b)

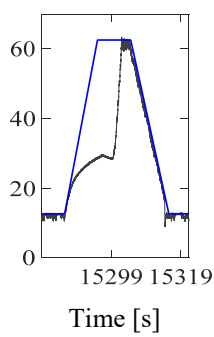

(c)
Fig. 15. Experimental results of P\&O, FMPC-MPPT, and DMPC-MPPT, respectively, under very low to medium irradiance EN50530 standard test "10\% - 50\%": (a) one repetition from the sequence before the last two sequences " $20 \mathrm{~W} / \mathrm{m}^{2} / \mathrm{s}$ ", (b) one repetition from the one before the last sequence " $30 \mathrm{~W} / \mathrm{m}^{2} / \mathrm{s}$ ", and (c) one repetition from the last sequence " $50 \mathrm{~W} / \mathrm{m}^{2} / \mathrm{s}$ ". the MPP in these sequences.

As it can be seen from Fig. 15 and Fig. 16, DMPC-MPPT operates with a significant oscillation under low irradiance levels, these oscillations are even bigger than the oscillations of $\mathrm{P} \& \mathrm{O}$. And that justifies why the statical efficiencies of this method are less than the efficiencies of the other methods presented in Table VI. But, from Tables III and IV, the simulation model did not reveal these oscillations. During low insolation levels the fill form factor decrease, and since the prediction model of DMPC-MPPT is performed based on the PV characteristic, some measurement noise, will cause to a deviation of the predicted variable out of the PV characteristic.

Fig. 17 shows the experimental results of FMPC-MPPT and DMPC-MPT where the system was operating under the STC and with model parameter misestimated. This figure shows that the efficiency of FMPC-MPPT decreased to $99.38 \%$ when

TABLE VI

EXPERIMENTAL RESULTS OF THE MPPT EFFICIENCIES UNDER EN50530 STANDARDS CONDITIONS USING BOOST CONVERTER $(\%)$

\begin{tabular}{cccc}
\hline \hline$\eta$ & P\&O & FMPC-MPPT & DMPC-MPPT \\
\hline$\eta_{\text {Euro }}$ & 99.73 & 99.76 & 99.68 \\
$\eta_{C E C}$ & 99.85 & 99.87 & 99.79 \\
$\eta_{\text {Dyn }}$ & 98.12 & 98.19 & 98.57 \\
\hline \hline
\end{tabular}
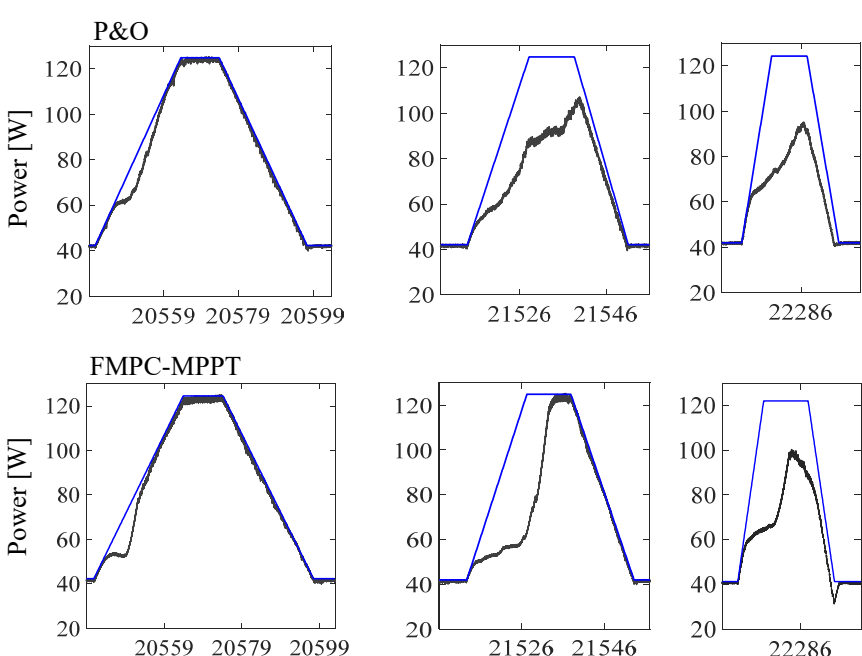

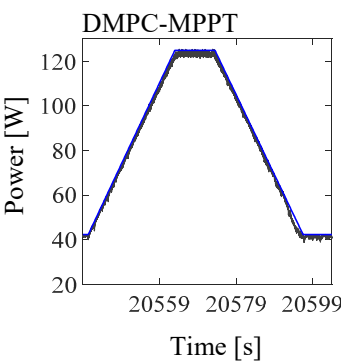

(a)

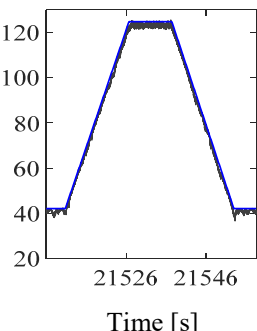

(b)

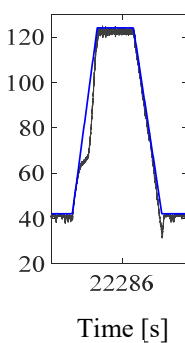

(c)
Fig. 16. Experimental results of P\&O, FMPC-MPPT, and DMPC-MPPT, respectively, under low to high irradiance EN50530 standard test " $30 \%$ 100\%": (a) one repetition from the sequence before the last two sequences " $30 \mathrm{~W} / \mathrm{m}^{2} / \mathrm{s}$ ", (b) one repetition from the one before the last sequence " $50 \mathrm{~W} / \mathrm{m}^{2} / \mathrm{s}$ ", and (c) one repetition from the last sequence " $100 \mathrm{~W} / \mathrm{m}^{2} / \mathrm{s}$ ". 


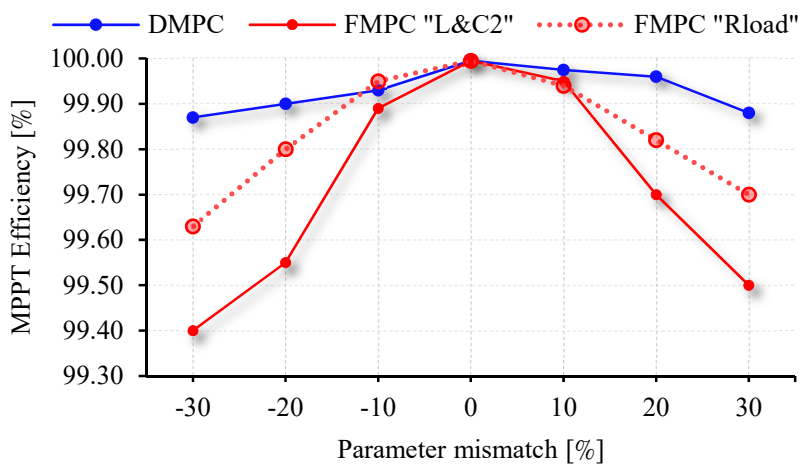

Fig. 17. Experimental results of FMPC-MPPT and DMPC-MPPT efficiencies under STC in case of model parameter mismatch " $L$ and $C_{2}$ ". The red dush line represents FMPC efficiencies with load value misestimated "Rload".

the system was working with $-30 \%$ model parameter mismatch, whereas DMPC-MPPT decreased to $99.86 \%$. When the parameters of the system were overestimated by $30 \%$, FMPC-MPPT exhibits a decreased efficiency of $99.50 \%$, whereas DMPC-MPPT decreased to $99.87 \%$. Also, it is worth noting that sensitivity to model parameter inaccuracy is asymmetrical. We can conclude from this figure that FMPCMPPT is again more influenced by the model parameter mismatch. And that, because FMPC-MPPT uses the model of the converter for the decision based on the difference between the references and the predicted variables, whereas DMPCMPPT uses the converter parameters just for the estimation of the shifting step size.

Table VII shows a summarized comparison of these methods, in terms of computational cost, dynamic performance, oscillation under low insolation levels, and model parameter dependency. During one sample period $T s$, the measurement, algorithm execution, and actuation times added all together should fit in. Also, since the gating pulses used to control the converter are generated directly from the control algorithm, the sampling frequency must be greater than or equal to the switching frequency [24]. These two aforementioned conditions are the boundaries that should be taken into account when selecting the sampling frequency. The use of the modulation stage makes the choice of the sampling time when implementing DMPC more flexible. Hence, the computation cost is highly dependent on the switching frequency of the converter rather than the used approach.

The processing time has been calculated by using dSpace Profiler program during the operation of the system. As can be seen from this table (VII), the processing time of the conventional $\mathrm{P} \& \mathrm{O}$ is less than the processing of MPC-MPPTs. On the other hand, the difference between FMPC and DMPC is only $0.35 \mu \mathrm{s}$. But, it can be estimated that in case of a 3phase converter, the difference between these two methods will extend, since the prediction in FMPC is going to be for each phase apart. It is worth noting that the below computation times include the full control algorithm and additional overhead by the dSpace system, not only the MPPT algorithm itself. We also expect that in case of implementation on a microcontroller with dedicated interrupts for the different control functions, differences in computational cost between $\mathrm{P} \& \mathrm{O}$ and MPC methods will increase.

\section{CONCLUSION}

In FMPC-MPPT, only the behavior of the converter based on its mathematical model is considered for performing the predictions. Since the reference tracked by FMPC is generated by using $\mathrm{P} \& \mathrm{O} / \mathrm{INC}$ algorithm, the oscillation in the output $\mathrm{PV}$ power under steady meteorological conditions will be inherited from $\mathrm{P} \& \mathrm{O} / \mathrm{INC}$. Also, under changing atmospheric conditions, the dynamic performance of FMPC-MPPT will be inherited from $\mathrm{P} \& \mathrm{O}$ as well. Hence, the application of FMPC on MPPT does not conquer the problems of the classical MPPTs. Indeed, the application of FMPC on MPPT overcome the drawbacks of the PI controller used in the voltage control loop of the MPPT (in case of voltage control).

DMPC-MPPT is less sensitive to model parameter mismatch, and it has a better dynamics compared to FMPCMPPT during rapid environmental condition changes. However, during low solar irradiance levels (when the PV curve's knee is flatter), and in real application, some noise measurement may lead to an extrapolation with a slope's sign opposite to the PV curve's slope sign. Therefore, the prediction will be in the wrong direction. After running several loops under these circumstances, a relatively high power oscillation will be produced at the terminals of the PV array.

As a general conclusion, the DMPC-MPPT method is advised for implementation instead of FMPC-MPPT, especially in sudden environmental conditions changing areas.

TABLE VII

COMPARISON OF DISCRETE MODEL PREDICTIVE CONTROL BASED MPPTS

\begin{tabular}{|c|c|c|c|c|c|c|c|c|c|}
\hline & \multicolumn{3}{|c|}{ Boost } & \multicolumn{3}{|c|}{ Z-source inverter } & \multicolumn{3}{|c|}{ Flyback } \\
\hline & $\mathrm{P} \& \mathrm{O}$ & FMPC & DMPC & $\mathrm{P} \& \mathrm{O}$ & FMPC & DMPC & $\mathrm{P} \& \mathrm{O}$ & FMPC & DMPC \\
\hline $\begin{array}{l}\text { Sampling frequency } \\
\text { (Computational cost) }\end{array}$ & Low & $\begin{array}{l}\text { Extremely } \\
\text { high }\end{array}$ & Very high & Low & High & High & Low & Very high & Very high \\
\hline Processing time & $5.58 \mu \mathrm{s}$ & $8.36 \mu \mathrm{s}$ & $8.71 \mu \mathrm{s}$ & - & - & - & - & - & - \\
\hline Dynamic performance & Poor & Poor & $\begin{array}{l}\text { Above } \\
\text { average }\end{array}$ & Poor & Poor & Average & Poor & Poor & $\begin{array}{l}\text { Above } \\
\text { average }\end{array}$ \\
\hline Oscillation under low insolations & Exist & Exist & Large & Exist & Exist & Large & Exist & Exist & Large \\
\hline Model parameter dependency & No & High & Exist & No & High & Exist & No & High & Exist \\
\hline
\end{tabular}




\section{REFERENCES}

[1] International Energy Agency. (2016). World Energy Investment Outlook |Special Report [Online]. Available: https://www.iea.org/ newsroom /news/2016/october/iea-raises-its-five-year-renewable-growth-forecast as -2015-marks-record-year.html.

[2] International Energy Agency. (2016). Technology Roadmap, Solar Photovoltaic Energy 2016 edition:[Online]. Available: https://www.iea.org/publications/freepublications/publication/WorldEne rgyOutlook2016ExecutiveSummaryEnglish.pdf.

[3] S. Sajadian, R. Ahmadi, "Model Predictive-Based Maximum Power Point Tracking for Grid-Tied Photovoltaic Applications Using a $Z$ Source Inverter," IEEE Trans. Power Electron., vol. 31, no. 11, pp. 7611-7619, Nov. 2016.

[4] D. Sera, L. Mathe, T. Kerekes, S. V. Spataru, and R. Teodorescu, "On the Perturb-and-Observe and Incremental Conductance MPPT Methods for PV Systems," IEEE J. Photovolt., vol. 3, no. 3, pp. 1070-1078, 2013

[5] N. Femia, G. Petrone, G. Spagnuolo and M. Vitelli, "A Technique for Improving P\&O MPPT Performances of Double-Stage Grid-Connected Photovoltaic Systems," in IEEE Trans. Ind. Electron., vol. 56, no. 11 , pp. 4473-4482, Nov. 2009

[6] M. A. Elgendy, B. Zahawi, and D. Atkinson, "Operating characteristics of the $\mathrm{P} \& \mathrm{O}$ algorithm at high perturbation frequencies for standalone PV systems," IEEE Trans. Energy Convers., vol. 30, no. 1, pp. 189-198, Mar. 2015.

[7] M. B. Shadmand, X. Li, R. S. Balog and H. A. Rub, "Model predictive control of grid-tied photovoltaic systems: Maximum power point tracking and decoupled power control," First Workshop on Smart Grid and Renewable Energy (SGRE), Doha, 2015, pp. 1-6.

[8] Y. Mahmoud, M. Abdelwahed and Ehab F. El-Saadany, "An Enhanced MPPT Method Combining Model-Based and Heuristic Techniques," IEEE Trans. Sustain. Energy, vol. 7, no. 2, pp. 576-585, April 2016.

[9] N. Femia, G. Petrone, G. Spagnuolo, and M. Vitelli, "Optimization of perturb and observe maximum power point tracking method," IEEE Trans. Power Electron., vol. 20, no. 4, pp. 963-973, Jul. 2005.

[10] A. Safari and S. Mekhilef, "Simulation and hardware implementation of incremental conductance MPPT with direct control method using cuk converter," IEEE Trans. Ind. Electron., vol. 58, no. 4, pp. 1154-1161, Apr. 2011.

[11] M. A. Elgendy, B. Zahawi, and D. J. Atkinson, "Assessment of the incremental conductance maximum power point tracking algorithm," IEEE Trans. Sustain. Energy, vol. 4, no. 1, pp. 108-117, Jan. 2013

[12] T. K. Soon and S. Mekhilef, "Modified incremental conductance MPPT algorithm to mitigate inaccurate responses under fast-changing solar irradiation level," Solar Energy, vol. 101, no. 0, pp. 333-342, 2014.

13] W. Xu, C. Mu and J. Jin, "Novel Linear Iteration Maximum Power Poin Tracking Algorithm for Photovoltaic Power Generation," in IEEE Trans. on Applied Superconductivity, vol. 24, no. 5, pp. 1-6, Oct. 2014.

[14] B. Subudhi and R. Pradhan, "A Comparative Study on Maximum Power Point Tracking Techniques for Photovoltaic Power Systems," IEEE Trans. Sustain. Energy, vol. 4, no. 1, pp. 89-98, Jan. 2013.

[15] A. Al Nabulsi and R. Dhaouadi, "Efficiency optimization of a DSPbased standalone PV system using fuzzy logic and dual-MPPT control," IEEE Trans. Ind. Info., vol. 8, no. 3, pp. 573-584, Aug. 2012.

[16] Syafaruddin, E. Karatepe, and T. Hiyama, "Artificial neural networkpolar coordinated fuzzy controller based maximum power point tracking control under partially shaded conditions," IET Renew. Power Gener., vol. 3 , no. 2 , pp. 239-253, Jul. 2009

[17] J. Holtz and S. Stadtfeld, "A predictive controller for the stator current vector of AC machines fed from a switched voltage source," Int. Power Electron. Conf., (IPEC), 1983.

[18] J. Rodriguez, M. P. Kazmierkowski, J. R. Espinoza, P. Zanchetta, H. Abu-Rub, H. A. Young, et al., "State of the Art of Finite Control Set Model Predictive Control in Power Electronics," IEEE Trans. Ind. Info., vol. 9, pp. 1003-1016, 2013.

[19] P. Cortes, A. Wilson, S. Kouro, J. Rodriguez, and H. Abu-Rub, "Model Predictive Control of Multilevel Cascaded HBridge Inverters," IEEE Trans. Ind. Electron. vol. 57, pp. 2691-2699, 2010.

[20] S. vazquez, J, i. leon, L. g. franquelo, J. rodrÍguez, H. A. young, A. marquez, and P. zanchetta, "Model predictive control: A review of its applications in power electronics," IEEE Ind. Electron. Mag, Vol.8, No. 1, pp. 16-31, 2014.

[21] M. Aleenejad, H. Mahmoudi, and R. Ahmadi, "A Modified Space Vector Modulation Method for Fault-Tolerant Operation of Multilevel Converters," IEEE Trans. Power Electron., vol. PP, pp. 1-1, 2015.
[22] P. Cortes, M. P. Kazmierkowski, R. M. Kennel, D. E. Quevedo, and J. Rodriguez, "Predictive control in power electronics and drives," IEEE Trans. Ind. Electron., vol. 55, no. 12, pp. 4312-4324, Dec. 2008.

[23] J. Rodríguez and P. Cortes, Predictive Control of Power Converters and Electrical Drives, 1st edition. New York: Wiley-IEEE Press, 2012.

[24] R. Errouissi, S. M. Muyeen, A. Al-Durra, and Siyu Leng. "Experimental Validation of a Robust Continuous Nonlinear Model Predictive Control Based Grid-Interlinked Photovoltaic Inverter," IEEE Trans. Ind. Electron., vol, 63.no 7: pp. 4495-4505. July 2016.

[25] R. Erase, S. M. Muyeen, A. Al-Durra, and S. Leng. "A Robust Continuous-Time MPC of a DC-DC Boost Converter Interfaced With a Grid-Connected Photovoltaic System." IEEE J. photovolt., vol. 6, no. 6: pp. 1619-1629, NOV 2016.

[26] M. B. Shadmand, R. S. Balog and H. Abu-Rub, "Model Predictive Control of PV Sources in a Smart DC Distribution System: Maximum Power Point Tracking and Droop Control," IEEE Trans. Energy Convers., vol. 29, no. 4, pp. 913-921, Dec. 2014.

[27] S. Sajadian and R. Ahmadi, "Distributed maximum power point tracking using model predictive control for solar photovoltaic applications," 2017 IEEE Applied Power Electronics Conference and Exposition (APEC), Tampa, FL, 2017, pp. 1319-1325.

[28] R. P. Aguilera and D. E. Quevedo, "On stability and performance of finite control set MPC for power converters," 2011 Workshop on Predictive Control of Electrical Drives and Power Electronics, Munich, 2011, pp. 55-62.

[29] R. P. Aguilera and D. E. Quevedo, "Predictive Control of Power Converters: Designs With Guaranteed Performance," in IEEE Trans. Ind. Info., vol. 11, no. 1, pp. 53-63, Feb. 2015.

[30] P. Cortes, J. Rodriguez, C. Silva, and A. Flores, "Delay compensation in model predictive current control of a three-phase inverter," IEEE Trans. Ind. Electron., vol. 59, no. 2, pp. 1323-1325, Feb. 2012.

[31] M. B. Shadmand, M. Mosa, R. S. Balog and H. A. Rub, "An improved MPPT technique for high gain DC-DC converter using model predictive control for photovoltaic applications," IEEE Applied Power Electro. Conf. and Exposition - APEC 2014, Fort Worth, pp. 2993-2999.

[32] O. Abdel-Rahim, H. Funato and J. Haruna, "An efficient MPPT technique with fixed frequency finite-set model predictive control," 2015 IEEE Energy Convers. Congress and Exposition (ECCE), Montreal, QC, pp. 6444-6449.

[33] M. B. Shadmand, M. Mosa, R. S. Balog and H. A. Rub, "Maximum power point tracking of grid connected photovoltaic system employing model predictive control," 2015 IEEE Applied Power Electro. Conf. and Expo., (APEC), Charlotte, NC, pp. 3067-3074.

[34] P. E. Kakosimos, A. G. Kladas. "Implementation of photovoltaic array MPPT through fixed step predictive control technique." Renewable Energy, vol. 36, PP. 2508-2514, 2011

[35] O. Abdel-Rahim and H. Funato, "Model Predictive Control based Maximum Power Point Tracking technique applied to Ultra Step-Up Boost Converter for PV applications," IEEE Innovative Smart Grid Technologies - Asia (ISGT ASIA), Kuala Lumpur, 2014, pp. 138-142.

[36] M. Metry, S. Bayhan, R. S. Balog, H. Abu Rub "Model Predictive Control for PV Maximum Power Point Tracking of Single-Phase sub Multilevel Inverter," Power and Energy Conf., Illinois (PECI), Feb. 2016.

[37] A. A. Abushaiba, S. M. M. Eshtaiwi and R. Ahmadi, "A new model predictive based Maximum Power Point Tracking method for photovoltaic applications," 2016 IEEE Int. Conf. Electro Information Technology (EIT), Grand Forks, ND, pp. 0571-0575.

[38] P. E. Kakosimos, A. G. Kladas, and S. N. Manias, "Fast PhotovoltaicSystem Voltage- or Current-Oriented MPPT Employing a Predictive Digital Current-Controlled Converter," IEEE Trans. Ind. Electron., vol. 60, no. 12, pp. 5673-5685, Dec. 2013.

[39] R. Kadri, J. P. Gaubert, and G. Champenois, “An improved maximum power point tracking for photovoltaic grid-connected inverter based on voltage-oriented control," IEEE Trans. Ind. Electron., vol. 58, no. 1, pp. 66-75, Jan. 2011.

[40] M. E. Ropp, S Gonzalez. "Development of a MATLAB/Simulink model of a single phase grid-connected photovoltaic system." IEEE Trans. on Energy Convers., vol. 24, no. 1: pp. 195-202, 2009.

[41] A. Bakeer, M. A. Ismeil, and M. Orabi. "A Powerful Finite Control SetModel Predictive Control Algorithm for Quasi Z-Source Inverter." IEEE Trans. Ind. Info., vol. 12, No 4: pp. 1371-1379. August 2016.

[42] M. Metry, M. B. Shadmand, R. S. Balog and H. Abu-Rub, "MPPT of Photovoltaic Systems Using Sensorless Current-Based Model Predictive 
Control," in IEEE Trans. Ind. App., vol. 53, no. 2, pp. 1157-1167, April 2017.

[43] K. Ishaque, Z. Salamb, and G. Laussc, "The performance of perturb and observe and incremental conductance maximum power point tracking method under dynamic weather conditions," Elsevier Trans. on Applied Energy, Vol. 119, pp. 228-236, April 2014.

[44] D. Sera, R. Teodorescu, J. Hantschel and M. Knoll, "Optimized Maximum Power Point Tracker for Fast-Changing Environmental Conditions," IEEE Trans. Indus. Electronics, vol. 55, no. 7, pp. 26292637, July 2008.

[45] M. Mosa, H. Abu Rub, M. E. Ahmed and J. Rodríguez, "Modified MPPT with using model predictive control for multilevel boost converter," IECON 2012 - 38th Annual Conf. on IEEE Ind. Electronics Society, Montreal, QC, pp. 5080-5085.

[46] M. A. Morales-Caporal, J. d. J. Rangel-Magdaleno, J. M. RamirezCortes, E. Tlelo-Cuatle and R. Morales-Caporal, "Control algorithm using trajectory-based MPC for MPPT application," IEEE Int. Autumn Meeting on Power, Electron. Comp. (ROPEC), 2015, Ixtapa, pp. 1-6.

[47] O. Lopez-Lapena, M. Teresa Penella, M. Gasulla, "A Closed-Loop Maximum Power Point Tracker for Subwatt Photovoltaic Panels," IEEE Indus. Electr. Mag, vol.59, no. 3, pp. 1588-1596, 2011.

[48] O. Abdel-Rahim and H. Funato, "An experimental investigation of modified predictive hysteresis control based MPPT strategy for PV applications," IEEE Energy Convers. Congress and Exposition (ECCE), Montreal, QC, 2015, pp. 6450-6454.

[49] Y. Yang and F. Blaabjerg, "A modified P\&O MPPT algorithm for single-phase PV systems based on deadbeat control," 6th IET Int. Conf. Power Electron., Machines and Drives (PEMD), Bristol, 2012, pp. 1-5.

[50] S. Kouro, P. Cortes, R. Vargas, U. Ammann, and J. Rodriguez, "Model predictive control-a simple and powerful method to control power converters,"IEEE Trans. Ind. Electron., vol. 56, no. 6, pp. 1826-1838, Jun. 2009.

[51] T. Geyer, G. Papafotiou, and M. Morari, "Model predictive direct torque control-Part I: Concept, algorithm, and analysis," IEEE Trans. Ind. Electron., vol. 56, no. 6, pp. 1894-1905, Jun. 2009

[52] G. Papafotiou, J. Kley, K. G. Papadopoulos, P. Bohren, and M. Morari,"Model predictive direct torque control-Part II: Implementation and experimental evaluation," IEEE Trans. Ind. Electron., vol. 56, no. 6, pp. 1906-1915, Jun. 2009.

[53] P. Fang Zheng, "Z-source inverter," IEEE Trans. Ind. Appl., vol. 39, no. 2, pp. 504-510, Mar./Apr. 2003.

[54] S. Miaosen, W. Jin, A. Joseph, P. Fang Zheng, L. M. Tolbert, and D.J. Adams, "Constant boost control of the Z-source inverter to minimize current ripple and voltage stress," IEEE Trans. Ind. Appl., vol. 42, no. 3 , pp. 770-778, May/Jun. 2006.

[55] S. Miaosen,W. Jin, A. Joseph, F. Z. Peng, L. M. Tolbert, and D. J. Adams, "Maximum constant boost control of the Z-source inverter," in Proc. IEEE Ind. Appl. Conf., 2004, pp. 1-147.

[56] O. Machado; P. Martin Sanchez; F. J. Rodriguez; E. Bueno, "A Neural Network-based Dynamic Cost Function for the Implementation of a Predictive Current Controller," in IEEE Trans. Ind. Inf, accepted.

[57] S. Sajadian and R. Ahmadi, "Distributed Maximum Power Point Tracking Using Model Predictive Control for Photovoltaic Energy Harvesting Architectures Based on Cascaded Power Optimizers," in IEEE J. Photovolt., vol. 7, no. 3, pp. 849-857, May 2017.

[58] R. Bründlinger, N. Henze, H. Häberlin, B. Burger, A. Bergmann, and F. Baumgartner, "prEN 50530 - The New European Standard for Performance Characterisation of PV Inverters," 24th European Photovoltaic Solar Energy Conf., Germany, Sep 2009, pp. 3105 - 3109.

[59] H. Häberlin, "New test procedure for Measuring Dynamic MPP Tracking Efficiency at Grid connected PV inverters", 24th European Photovoltaic Solar Energy Conf., Germany, Sep 2009, pp. 3631-3637.

[60] S. B. Kjaer, "Evaluation of the 'Hill Climbing'and the 'Incremental Conductance'maximum power point trackers for photovoltaic power systems," IEEE Trans. Energy. Convers., vol. 27, no. 4, pp. 922-929, Dec. 2012.

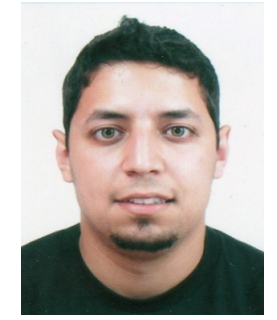

Abderezak Lashab (S'13) received the Bachelor and Master diplomas in Electrical Engineering from Université des Frères Mentouri Constantine, Constantine, Algeria, in,2010 and 2012, respectively. He is currently a Ph.D. Student with the Department of Electrical Engineering, at the same university. His current research interests include control, modeling, and diagnostics of photovoltaic (PV) power systems, and power electronics.

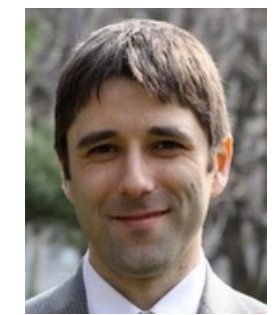

Dezso Sera (S'05-M'08 -SM'15) received his B.Sc. and M.Sc. degrees in Electrical Engineering from the Technical University of Cluj, Romania in 2001 and 2002, respectively; MSc in Power Electronics and $\mathrm{PhD}$ on PV systems from Aalborg University, Denmark, Department of Energy Technology, where he currently works as Associate Professor. Since 2009 he has been programme leader of the Photovoltaic Systems Research Programme (www.pv-systems.et.aau.dk) at the same dept. His research interests include modelling, characterisation, diagnostics and maximum power point tracking (MPPT) of PV arrays, as well as power electronics and grid integration for PV systems.

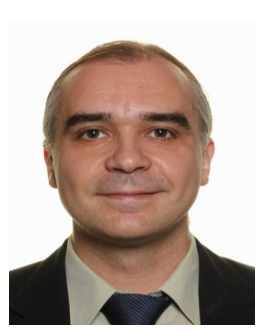

Josep M. Guerrero (S'01-M'04-SM'08-FM'15) received the B.S. degree in telecommunications engineering, the M.S. degree in electronics engineering, and the Ph.D. degree in power electronics from the Technical University of Catalonia, Barcelona,in 1997, 2000 and 2003, respectively. Since2011, he has been a Full Professor with the Department of Energy Technology, Aalborg University, Denmark, where he is responsible for the Microgrid Research Program (www.microgrids.et.aau.dk).

His research interests are oriented to different microgrid aspects, including power electronics, distributed energy-storage systems, hierarchical and cooperative control, energy management systems,smart metering and the internet of things for $\mathrm{AC} / \mathrm{DC}$ microgrid clustersand islanded minigrids; recently specially focused on maritime microgrids for electrical ships, vessels, ferries and seaports. Prof.Guerrero is an Associate Editor for the IEEE TRANSACTIONS ON POWER ELECTRONICS, the IEEE TRANSACTIONS ON INDUSTRIAL ELECTRONICS, and the IEEE Industrial Electronics Magazine, and an Editor for the IEEE TRANSACTIONS on SMART GRID.

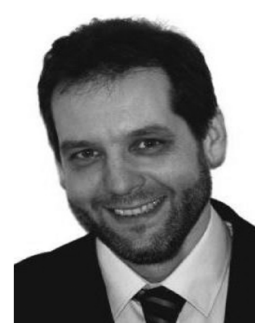

Laszlo Mathe (S'07-M'10) received the B.Sc. degree in electrical engineering and the M.Sc. degree from the Technical University of Cluj-Napoca, ClujNapoca, Romania, in 2000 and 2002, respectively, and the Ph.D. degree in electrical engineering from the Department of Energy Technology, Aalborg University, Aalborg, Denmark, in 2010. Between 2002 and 2007, he was a Control Development Engineer. He is currently an Associate Professor at Aalborg University. His current research interests include control and design of power converters, control of electrical drives, photovoltaic systems, modulation techniques (MMC, two level inverters), vehicle electrification.

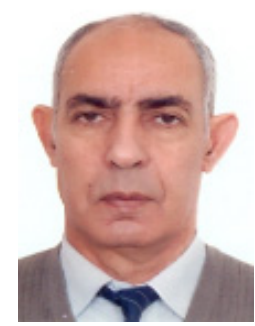

Aissa Bouzid received his $\mathrm{PhD}$ degree in Electrical engineering from Paris 6 University, France in 1992. $\mathrm{He}$ is currently the dean of the faculty of engineering at Université des Frères Mentouri, Constantine, Algeria and Full Professor with the Department of Electrical Engineering, at the same university. His current research interests include control, modeling, and diagnostics of both photovoltaic and wind power systems, and power electronics. 